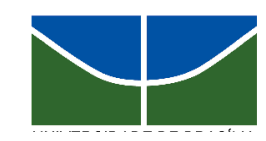

UNIVERSIDADE DE BRASÍLIA

Centro de Excelência em Turismo

Pós-graduação Lato Sensu

Curso de Especialização em Gastronomia e Saúde

\title{
ENSAIO SOBRE A IMPORTÂNCIA DO TREINAMENTO PARA MANIPULADORES DE ALIMENTOS NOS SERVIÇOS DE ALIMENTAÇÃ̃ BASEADA NA RDC N.o 216/2004
}

\author{
Vitor Hugo Rocha de Vasconcelos
}

Orientadora: Profa. Dra. Wilma Maria Coelho Araújo

Brasília-DF 


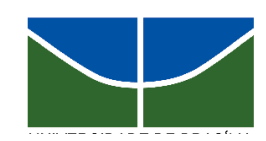

UNIVERSIDADE DE BRASÍLIA

Centro de Excelência em Turismo

Pós-graduação Lato Sensu

Curso de Especialização em Gastronomia e Saúde

Vitor Hugo Rocha de Vasconcelos

Orientadora: Profa. Dra. Wilma Maria Coelho Araújo

\section{ENSAIO SOBRE A IMPORTÂNCIA DO TREINAMENTO PARA MANIPULADORES DE ALIMENTOS NOS SERVIÇOS DE ALIMENTAÇÃO BASEADA NA RDC N. 216/2004}

Monografia apresentada ao Centro de Excelência em Turismo - CET, da Universidade de Brasília - UnB, como requisito parcial para obtenção do grau de Especialista em Gastronomia e Saúde.

\section{Brasília-DF}


Vasconcelos, Vitor Hugo Rocha de

Ensaio sobre a importância do treinamento para manipuladores de alimentos nos serviços de alimentação baseada na RDC n. ${ }^{\circ} 216 / 2004$ / Vitor Hugo Rocha de Vasconcelos. - Brasília, 2008.

ix, $17 \mathrm{f}$ : : il.

Monografia de Especialização apresentada ao Curso de Especialização em Gastronomia e Saúde - Universidade de Brasília, Centro de Excelência em Turismo.

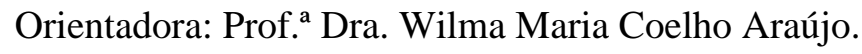

1. Serviços de Alimentação. 2. Manual de Boas Práticas. 3. Capacitação. 


\section{UNIVERSIDADE DE BRASÍLIA}

Centro de Excelência em Turismo

Pós-graduação Lato Sensu

Curso de Especialização em Gastronomia e Saúde

\section{VITOR HUGO ROCHA DE VASCONCELOS}

\section{Aprovado por:}

Professora Orientadora: Dra. Wilma Maria Coelho Araújo

Professora Examinadora: Dra. Rita de Cássia Coelho de Almeida Akutsu

Professora Examinadora: MSc. Karla Lisboa Ramos

Brasília, 20 de outubro de 2008 


\section{DEDICATÓRIA}

Aos meus amados pais: Germano e Cleomar; pelo exemplo de dignidade, persistência e coragem. Pela dedicação e apoio aos meus impulsos e, acima de tudo, o incentivo necessário à minha vida profissional e estudantil. Minha eterna gratidão.

Aos meus queridos irmãos: Luís Antônio e Lívia Maria; neste caso, a gratidão é pela união e camaradagem. Definitivamente a união faz a força.

Aos meus amigos, pela tolerância e bondade. 


\section{AGRADECIMENTOS}

Agradeço a Deus que em todos os momentos se faz presente em minha vida.

À professora orientadora Dra. Wilma Maria Coelho Araújo, pelas instruções e incentivos recebidos durante a confecção do trabalho. 
O futuro é construído pelas nossas decisões diárias, inconstantes e mutáveis, e cada evento influencia a todos os outros.

Alvin Tofler 


\section{RESUMO}

A higiene e segurança alimentar em uma empresa de alimentos visa garantir uma adequada condição higiênico-sanitária dos produtos elaborados, sem oferecer riscos à saúde do consumidor, sob condições previstas pela legislação vigente. O objetivo deste trabalho é fazer um ensaio sobre a importância do treinamento dos manipuladores de alimentos em uma unidade de serviço de alimentação que possibilite uma prática organizacional baseada no conhecimento dos principais agentes etiológicos que causam as doenças transmitidas por alimentos. O trabalho ressalta que há uma premente necessidade de auxiliar os manipuladores e donos de restaurantes no tratamento e garantia da qualidade dos produtos oferecidos. $\mathrm{O}$ trabalho foi baseado em revisões bibliográficas existentes sobre o assunto. Do ponto de vista metodológico, o trabalho faz uma abordagem bibliográfica, tendo como subsídios consistentes a RDC 216/2004; livros; meios virtuais de pesquisa .

Palavras-chave: Serviços de Alimentação, higiene, segurança alimentar, RDC 216/2004, boas práticas (BP), procedimentos operacionais padronizados (POP's). 


\begin{abstract}
The hygiene and alimentary security in a food company aim at to guarantee a good hygienical-sanitary condition, not offering risks to the health of the consumer, under decisive conditions for the food production inside of the standards recommended for the current law of RDC 216, 15.9.2004 (Direction Student body of the National Agency of Sanitary Monitoring - ANVISA). For in such a way, it is basic that if it makes an analysis of the establishment "restaurant", considering all its peculiarities. The central objective of this article is to present a proposal of orientation, that makes possible one practical organizational to the employees and manipulators of foods, and knowledge of the main etiologic agent that cause DTA' s. The work stands out that it has a pressing necessity of assisting the manipulators and owners of restaurants in the treatment and guarantee of the offered product quality. The work was based on existing bibliographical revisions on the subject. Of the methodological point of view , the work makes a bibliographical boarding, having as consistent subsidies RDC 216/2004; books; virtual ways of research.
\end{abstract}

Key - Words: Services of Feeding, hygiene, alimentary security, illnesses transmitted for foods (DTA's), RDC 216/2004, good practical (BP), standardized operational procedures (POP's). 
SUMÁRIO

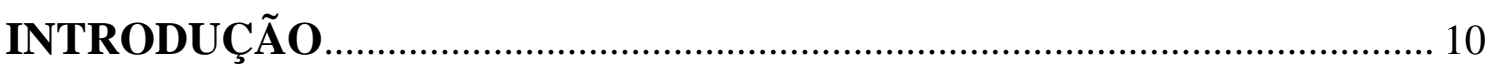

Serviços de Alimentação e Saúde Pública ……………………………………..... 12

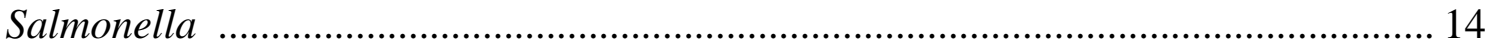

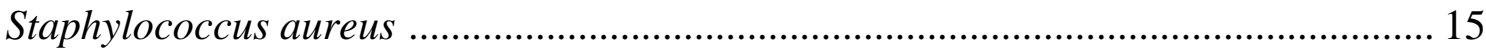

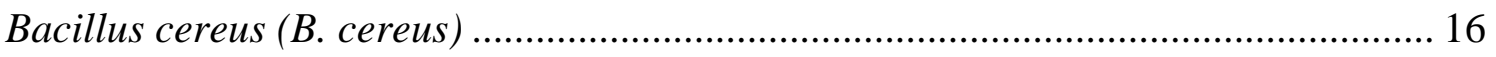

Clostridium perfringens (Cl. perfringes) ………………........................................ 17

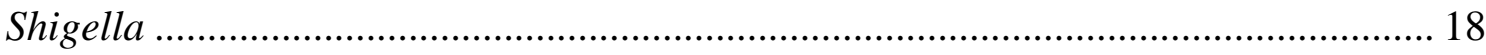

Escherichia coli Patogênica ............................................................................... 19

Sistema de Vigilância Epidemiológica das Doenças Transmitidas

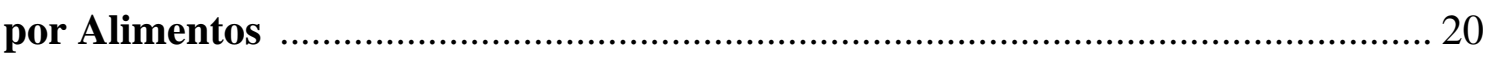

A RDC como Instrumento de Controle de Qualidade dos Alimentos ......... 21

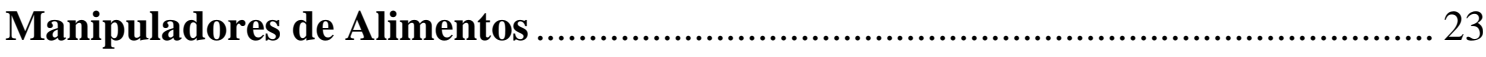

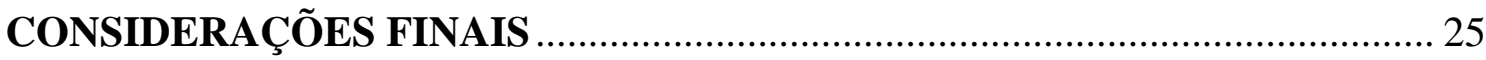

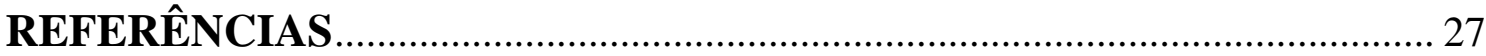

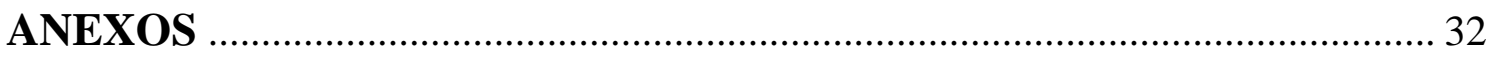




\section{INTRODUÇÃO}

A utilização dos serviços de alimentação ${ }^{1}$ tem se difundido como uma prática comum entre pessoas de diferentes níveis sociais e faixa etária. Aliado a este crescimento surgem diversas preocupações, tanto por parte dos consumidores como por parte dos fornecedores de alimentos. Alguns dos pontos que merecem destaque são os problemas relacionados à falta de higienização e os riscos de uma alimentação imprópria que pode acarretar em transmissão de doenças. A ocorrência de doenças transmitidas por alimentos vem aumentando de modo significativo, mesmo em países desenvolvidos, apesar dos avanços tecnológicos nas áreas de produção e controle de alimentos. De acordo com o Center for Disease Control and Prevention (CDC, 2001) tem sido descrita mais de duzentas doenças.

Vários são os fatores que contribuem para a ocorrência dessas doenças, entre os quais: o crescente aumento da população, a existência de grupos populacionais vulneráveis ou mais expostos, o processo de urbanização desordenado e a necessidade de produção de alimentos em grande escala. Contribui ainda, o deficiente controle dos órgãos públicos e privados, no tocante à qualidade dos alimentos ofertados às populações (CENEPI-MS, 2001). Outros fatores ainda são acrescentados ao aumento dessas incidências: maior exposição das populações a alimentos destinados ao pronto consumo coletivo, a utilização de novas modalidades de produção, o aumento no uso de aditivos alimentares e a mudança de hábitos alimentares, sem deixar de considerar as mudanças ambientais, a globalização e as facilidades atuais de deslocamento da população (CENEPI-MS, 2001).

A multiplicidade de agentes causais associadas aos fatores citados resulta em número significativo de possibilidades para a ocorrência dessas patologias, infecções ou intoxicações que podem se apresentar de formas crônica ou aguda, com características de surto ou de casos isolados, com distribuição localizada ou disseminada e com formas clínicas diversas (CENEPIMS, 2001).

Apesar da comprovada relação de várias doenças com a ingestão de alimentos contaminados, do elevado número de internações hospitalares e a persistência de altos índices de mortalidade infantil por diarréia, pouco se conhece sobre a real magnitude do problema, devido à precariedade das informações disponíveis (CENEP-MS, 2001).

\footnotetext{
${ }^{1}$ Segundo a RDC n. ${ }^{2}$ 216/04, Serviço de Alimentação é onde se realizam algumas das seguintes atividades: manipulação, preparação, fracionamento, armazenamento, distribuição, transporte, exposição à venda e entrega de alimentos preparados ao consumo, tais como cantinas, bufês, comissarias, confeitarias, cozinhas industriais, cozinhas institucionais, delicatéssens, lanchonetes, padarias, pastelarias, restaurantes, rotisserias e congêneres.
} 
De acordo com registros da Organização Mundial da Saúde (OMS) são detectados anualmente, nos países em desenvolvimento, mais de um bilhão de casos de diarréia em crianças menores de 5 anos, dos quais 5 milhões evoluem para o óbito; considerando que as informações epidemiológicas são subnotificadas, estima-se que apenas 1 a 10\% dos casos são computados pelas estatísticas oficiais.

Uma Pesquisa realizada em 2002 pelo Instituto Ethos de Empresas e Responsabilidade Social identificou que, dentre as três atitudes mais citadas que levam um consumidor a não consumir mais produtos e serviços de dada empresa, a mais relevante se refere àquelas situações que causaram danos à saúde dos consumidores. Cada dia mais consciente dos seus direitos e do seu poder, os consumidores vêm aos poucos assimilando este conceito na hora de optar por um produto ou serviço.

O presente estudo visa contribuir para disseminar a importância do treinamento dos manipuladores de alimentos nos serviços de alimentos como estratégia para prevenir o surgimento das doenças transmitidas por alimentos, para que assim possa o gastrônomo estabelecer medidas preventivas e reduzir o impacto deste agravo à população e ao sistema de saúde. Objetivamente, o ensaio visa discorrer sobre os riscos que o estabelecimento e seus clientes podem correr ao não aplicar as práticas da boa higiene na manipulação dos alimentos ofertados com base na legislação vigente.

\section{METODOLOGIA}

O trabalho se refere à elaboração de um ensaio, que se caracteriza por um estudo formal, discursivo e concludente, porém breve a respeito de certo tema (WIKIPEDIA, 2008). Justifica-se pela abundância de artigos sobre o assunto, mas nesse caso se limita aos serviços de alimentação. A referência para o estudo é a Resolução da Diretoria Colegiada (RDC) n. ${ }^{\circ} 16 / 04$ que regulamenta estes serviços para o constante aperfeiçoamento das ações de controle sanitário na área de alimentos visando a proteção à saúde da população, considerando a necessidade de harmonização da ação de inspeção sanitária em serviços de alimentação, considerando a necessidade de elaboração de requisitos higiênico-sanitários gerais para serviços de alimentação aplicáveis e é aplicado em todo território nacional.

O método de pesquisa consistiu em pesquisa exploratória na base de dados Google e Google Acadêmico, utilizando como palavras-chaves os termos "serviços de alimentação", "RDC 216/04", “toxinfecções alimentares”, "treinamento de manipuladores”, “doenças transmitidas por alimentos", no idioma português. 


\section{DESENVOLVIMENTO}

\section{Serviços de Alimentação e Saúde Pública}

Para os dias atuais, a refeição fora de casa deixou de ser uma opção de lazer e passou a ser uma questão de necessidade. Para atender a essa demanda, surgiram os serviços de alimentação e os de terceirização, provavelmente em função do novo papel das mulheres que passaram a buscar a independência econômica e a realização profissional por meio de um trabalho remunerado, pela forte necessidade de auxílio financeiro familiar, bem como, em virtude das diversas ocorrências políticas e governamentais que vieram a alterar as necessidades de sobrevivência e bem-estar da sociedade (OLIVEIRA; CAMPOS, 2006).

Estima-se que no Brasil, a cada cinco refeições, uma é feita fora de casa; na Europa duas em cada seis e, nos EUA, uma em cada duas (AKUTSU et al., 2005). Segundo Pesquisa de Orçamento Familiar (POF), realizada pelo Instituto Brasileiro de Geografia e Estatística (IBGE 2002;2003), nas grandes cidades brasileiras a população gasta em média $24 \%$ das despesas alimentares em consumo fora do domicílio, o que tende a aumentar já que o país está em crescente desenvolvimento econômico. Nos Estados Unidos, esta porcentagem aumenta para $46,2 \%$ das despesas alimentares.

Aliado à expansão dos serviços alimentares, ao crescente aumento das populações, à existência de grupos populacionais vulneráveis ou mais expostos, aos processos de urbanização desordenados, à necessidade de produção em grande escala de alimentos e ao deficiente controle dos órgãos públicos e privados no tocante à qualidade dos alimentos ofertados às populações surge à preocupação com as doenças transmitidas por alimentos (MANUAL VEDTA, 2005), segundo a Secretaria de Vigilância em Saúde (SVS).

DTA é um termo genérico, aplicado a uma síndrome, geralmente, constituída de anorexia, náuseas, vômitos e/ou diarréia. As doenças transmitidas por alimentos são atribuídas à ingestão de alimentos ou água contaminados por bactérias, vírus, parasitas, toxinas, prions, agrotóxicos, produtos químicos e metais pesados (Boletim Eletrônico Epidemiológico, 2005).

As doenças provocadas por alimentos, mais comumente, sintomas relacionados ao aparelho digestivo. No entanto, também podem ocorrer afecções extra-intestinais em diferentes órgãos e sistemas, como meninges, rins, fígado, sistema nervoso central, terminações nervosas periféricas e outros. São responsáveis atualmente pela maior parte dos surtos de diarréia em quase todos os países. O desenvolvimento econômico e a globalização do mercado mundial, as alterações nos hábitos alimentares, com a crescente utilização de 
alimentos industrializados ou preparados fora de casa alteraram o perfil epidemiológico dessas doenças, expondo a população a vários tipos de contaminantes (OPAS, 2001).

Conforme relatam Silva et al. (2004) em razão do fator desemprego tem aumentado algumas modalidades de prestação de serviços comerciais de alimentação; são inúmeros os estabelecimentos ou pessoas físicas que ingressam nesse ramo. E permanecem não apenas como clandestinos, mas desconhecendo as boas práticas de fabricação/ preparação/manipulação de alimentos, os fatores de risco e perigos, o que constitui importante desafio para o controle sanitário.

Os sintomas e quadros clínicos ocorrem de acordo com o agente etiológico e envolvem sintomas de desconforto intestinal e quadros como desidratação grave, diarréia, insuficiência renal aguda e insuficiência respiratória - botulismo (SVS, 2005). O quadro 1 apresenta os principais agentes etiológicos causadores das doenças transmitidas por alimentos, com detalhamento sobre o período de incubação, sinais e sintomas, principais alimentos envolvidos e fatores que contribuem para a ocorrência de surtos (Anexo 1). Apesar de o principal local de ocorrência ser ainda o domicílio, restaurantes, refeitórios, bufês e outros serviços de alimentação têm sido responsáveis por um importante percentual de surtos de diarréia ou toxinfecções alimentares (CVE, 2002).

A suscetibilidade das ocorrências de doenças é geral, mas crianças, idosos e imunodeprimidos têm suscetibilidade aumentada e, normalmente, não conferem imunidade duradoura. Os mecanismos patogênicos envolvidos podem se manifestar por meio de: infecções transmitidas por alimentos, que são doenças que resultam da ingestão de alimentos que contêm microorganismos patogênicos vivos, como salmoneloses, hepatite viral tipo A e toxoplasmose. Intoxicações causadas por alimentos que ocorrem quando as toxinas estão presentes no alimento ingerido. Essas toxinas, na maioria das vezes, não possuem cheiro ou sabor e são capazes de causar doenças depois que o microorganismo é eliminado. Algumas toxinas podem estar presentes, de maneira natural, no alimento, como no caso de alguns fungos ou peixes. Exemplos: botulismo e toxina do Staphylococcus aureus (SVS, 2005).

Na cadeia de transmissão de doenças, os alimentos são considerados veículos dos agentes infecciosos e tóxicos e podem ser contaminados durante todas as etapas da cadeia alimentar por perigos biológicos (bactérias, vírus e parasitas), químicos (agrotóxicos, desinfetantes) e físicos (prego, pedaços de madeira, vidro, etc.). Entre as principais formas de contaminação, destacam-se a manipulação e a conservação inadequadas dos alimentos. Assim, os manipuladores representam, por conseguinte, um importante elo na cadeia 
epidemiológica. Entre os perigos biológicos destacam-se aqueles relacionados à presença de organismos como:

\section{Salmonella}

Salmonella representa um grupo de bactérias que pode causar doença diarréica e, geralmente, é encontrada em alimentos de origem animal, como carnes, leite e derivados, ovos, entre outros. Casos relacionados ao consumo de ovos e ou derivados, envolvem o consumo de saladas ã base de ovos (maionese), sorvetes e outras sobremesas de fabricação caseira, além de produtos de panificação e confeitaria (CÂMARA, 2002).

As doenças causadas por Salmonella se subdividem em três grupos: a febre tifóide, causada por Salmonella typhi, as febres entéricas, causadas pela Salmonella paratyphi (A, B e C) e as enterocolites ou salmoneloses, causadas pelas demais Salmonellas (FRANCO; LANDGRAF, 1996).

Os sintomas principais são: diarréia, febre, cefaléia, cólica abdominal (US FDA, 2001). O período de incubação varia, em geral, de 12 até 72 horas após consumo de alimentos contaminados; com duração de quatro a sete dias (CÂMARA, 2002).

O gênero Salmonella pertence à família Enterobacteriaceae e compreende bacilos gram- negativos não produtores de esporos. São aneróbios facultativos, a maioria é móvel, através de flagelos peritríquios, exceção feita à $S$. pullorum e à $S$. gallinarum, que são imóveis. $\mathrm{O}$ pH ótimo para multiplicação das salmonelas fica próximo de 7,0, sendo que valores superiores a 9,0 e inferiores a 4,0 são bactericidas. Não toleram concentrações de sal superiores a 4\%. O nitrito é inibitório e seu efeito é acentuado pelo pH ácido. A temperatura ideal para multiplicação de Salmonella é $35-37^{\circ} \mathrm{C}$, sendo o mínimo de $7^{\circ} \mathrm{C}$ e máxima de $47^{\circ} \mathrm{C}$, a atividade de água é maior que 0,94 (CÂMARA, 2002).

A Salmonella thyphimurim é um dos principais sorotipos isolados em casos esporádicos ou surtos no Brasil e está associada a meningites, especialmente em crianças (TRABULSI; CAMPOS; LORENÇO, 1999). Representa um risco para a população que consome alimentos contaminados por ela devido ao seu potencial invasivo e, portanto, eminentemente patogênico (ALMEIDA; FRANCO, 2003). Existem aproximadamente 2.000 sorotipos diferentes de Salmonella. Os mais comuns, atualmente, no mundo são: Salmonella Enteritidis e Salmonella Typhimurium, sendo que a Salmonella Typhimurium fagotipo DT 104 é considerada um patógeno emergente e altamente virulento, resistente a vários antibióticos (US- FDA, 2001).

A Salmonella ocupa o segundo lugar como agente etiológico mais envolvido em doença diarreica (CDC, 2001). No Brasil, em estudo realizado em São Paulo, a salmonela foi 
à terceira bactéria mais isolada em crianças menores de um ano de idade com diarréia aguda (VERONESI; FOCACCIA, 1999).

\section{Staphylococcus aureus}

As bactérias do gênero Staphylococcus são cocos gram positivas, pertencentes à família Micrococcaceae, são anaeróbias facultativas e aeróbias. Característica peculiar à este tipo de bactéria é explicitada por Franco e Landgraf (1996) ao revelarem que quanto mais baixa for a temperatura, maior será o tempo necessário para a produção de enterotoxina. Em condições ótimas, a enterotoxina torna-se evidente em quatro a seis horas, explicam os autores.

Dezenove espécies fazem parte deste gênero, e dentre estas, as seguintes apresentam interesse em microbiologia de alimentos: S. aureus, S. hyicus, S. chromogens e $S$. intermedius, sendo $S$. aureus o mais importante. Com exceção de $S$. chromogens, as demais espécies apresentam testes positivos para coagulase e termonuclease (CÂMARA, 2002).

O S. aureus pode ser encontrado no solo, água, ar, no homem, e nos animais. Em seu principal reservatório, o homem, pode ser encontrado nas fossas nasais, de onde se propaga direta ou indiretamente para a pele e feridas (CÂMARA, 2002).

As bactérias deste gênero são tolerantes a concentrações de $10 \%$ a $20 \%$ de cloreto de sódio e nitratos, o que torna os alimentos curados veículos potenciais para as mesmas (FRANCO; LANDGRAF, 1996).

O S. aureus é um patógeno que possui capacidade de crescer em um teor de umidade bastante variável, ou seja, na mais ampla faixa de atividade de água (0,83 a 0,99), em condições aeróbias. A produção de enterotoxina é possível a partir de uma atividade de água de 0,86, sendo a ótima 0,99 (CÂMARA, 2002).

O período de incubação de um surto varia de trinta minutos a oitos horas, sendo a média de duas a quatro horas, após a ingestão do alimento contaminado (FRANCO; LANDGRAF, 1996).

O S. aureus tem potencial para causar intoxicação no consumidor mediante ingestão de alimentos que apresentem a enterotoxina estafilocócica preformada, portanto, o agente causador dos sintomas, não é a bactéria, mas sim suas toxinas: A, B,C1 , C2 ,C3 ,D ,E e TST.

As toxinas podem ser identificadas quando números iguais ou maiores que 104 células de S. aureus estão ou estiveram presentes no alimento (CÂMARA, 2002).

As cepas de $S$. aureus enterotoxigênicas podem encontrar-se nos alimentos a partir de sua obtenção primária, em especial nos de origem animal, (um exemplo típico é a mastite 
estafilocócica do gado leiteiro), ou chegar posteriormente durante o processamento, a partir dos manipuladores.

A manipulação inadequada dos alimentos por parte dos portadores da bactéria ou por pessoas com feridas nos braços e mãos, constitui a principal fonte de contaminação dos alimentos com estafilococos (CÂMARA, 2002).

Câmara (2002) aponta a $S$. aureus como o produtor de enterotoxinas e toxina TSST (Toxina da Síndrome do Choque Tóxico) na garganta e fossas nasais de funcionário da cozinha e copa de hospitais.

Para prevenir a intoxicação estafilocócica, é importante além de manter a saúde dos manipuladores, manter os alimentos sob refrigeração, pois desta forma impede-se a multiplicação bacteriana e conseqüentemente a produção de enterotoxina, evitando os surtos de intoxicação ( FRANCO; LANDGRAF, 1996) .

\section{Bacillus cereus (B. cereus)}

O B. cereus é um microrganismo que se encontra amplamente distribuído no meio ambiente, sendo o solo seu reservatório natural, por esta razão contamina facilmente a vegetação, cereais e derivados de cereais, alimentos, águas naturais, leite, produtos lácteos, e condimentos (CÂMARA, 2002).

Em estudos feitos com arroz cozido, esporos de B. cereus apresentaram um tempo de geração de 26 A 57minutos quando a temperatura foi mantida próxima de $30^{\circ} \mathrm{C}$. (FRANCO;LANDGRAF, 1996).

Os fatores de virulência do B. cereus estão relacionados com a produção de várias toxinas extracelulares, entre elas uma toxina diarréica termolábil. Este microrganismo tem sido responsável por $1 \%$ a $23 \%$ dos casos relatados na literatura. Podem apresentar duas formas clínicas: a síndrome diarréica e a emética (CÂMARA, 2002).

A síndrome diarréica caracteriza-se por um período de incubação que varia de 8 a 16 horas e seus principais sintomas são: diarréia intensa, dores abdominais, tenesmos retais, raramente ocorrendo náuseas e vômitos. A duração da doença é de 12 a 24 horas; geralmente está associada ao consumo de alimentos de composição protéica, contaminados com aproximadamente $106 \mathrm{UFC/g}$ (Unidades Formadoras de Colônias /grama). Estes microrganismos podem fazer parte da flora fecal, dependendo do tipo de alimento e da sazonalidade, principalmente no verão; entretanto não coloniza o intestino, não persistindo por longos períodos (FRANCO; LANDGRAF, 1996).

A síndrome emética caracteriza-se por um período de incubação curto, de 1 a 5 horas, causando vômitos, náuseas e mal estar geral, com 6 a 24 horas de duração. Esta síndrome está 
associada a alimentos com alto teor de amido e que contenham número elevado de microrganismos viáveis de B. cereus (maior ou igual a 106UFC/g) (CÂMARA, 2002).

ALMEIDA et al. (2001), observaram elevada ocorrência de B. cereus em farinha de mandioca, em diferentes alimentos a base de amido.

O consumo de alimentos recém preparados não oferece risco. Dentre as várias formas de tratamento térmico, o cozimento em vapor sob pressão, a fritura e o assar em forno quente destroem tanto células vegetativas quanto esporos. $\mathrm{O}$ cozimento em temperaturas inferiores a $100^{\circ} \mathrm{C}$ pode não ser eficaz para a destruição de todos os esporos de B. cereus (FRANCO; LANDGRAF, 1996).

A intoxicação alimentar causada por B. cereus, pode ocorrer quando alimentos preparados são mantidos à temperatura ambiente por várias horas antes do consumo (CÂMARA, 2002).

\section{Clostridium perfringens (Cl. perfringens)}

Este microrganismo tem grande facilidade de ser encontrado no intestinal do homem e de muitos animais. Sua ampla distribuição na natureza é devida aos esporos que o $\mathrm{Cl}$. perfringens produz, altamente resistentes às condições ambientais (FRANCO; LANDGRAF, 1996).

As células vegetativas de $\mathrm{Cl}$. perfringens perdem rapidamente sua viabilidade em temperaturas de congelamento, porém os esporos não demonstram a mesma sensibilidade que a forma vegetativa em baixas temperaturas (CÂMARA, 2002).

O Cl. perfringens é responsável por dois tipos diferentes de toxinfecção alimentar:

- As de forma clássica - são dores abdominais agudas, diarréia com náuseas e febre, sendo os vômitos raros. Aparecem entre 8 a 12 horas após a ingestão do alimento contaminado, cuja duração é de 12 a 24 horas;

- As enterite necrótica, bem mais grave e rara. Os sintomas são dores abdominais agudas, diarréia sanguinolenta e inflamação necrótica do intestino delgado, sendo freqüentemente fatal (FRANCO; LANDGRAF, 1996).

$\mathrm{O}$ relatos de $\mathrm{Cl}$. perfringens como agente de intoxicação alimentar tem locais de ocorrência escolas, hospitais e restaurantes, porém não apresenta nenhuma prevalência de sazonalidade. Os alimentos comumente associados com $\mathrm{Cl}$. perfringens são : carnes e produtos cárneos, leite e derivados, peixes e produtos de pescado e vegetais. Em carnes cruas , a presença deste microrganismo indica más condições higiênicas no abate; já em carnes cozidas, uma baixa contagem reflete o nível de contaminação da matéria prima e uma contagem elevada indica processamento ou cozimento inadequado (CÂMARA, 2002). 
Leite e produtos de leite pasteurizado podem raramente estar contaminados por $\mathrm{Cl}$. perfringens oriundos das fezes do animal. A estocagem em temperaturas elevadas contribui para a esporulação do microrganismo; $\mathrm{O}$ isolamento de $\mathrm{Cl}$. perfrinfens em peixe é considerado um incidente, ou seja, falhas durante o processamento e preparo (CÂMARA, 2002).

\section{Shigella}

Bactérias do gênero Shigella são pertencentes à família Enterobacteriaceae. Este gênero é constituído por quatro espécies. Cada uma delas possui distintos sorogrupos: $S$. dysenteriae (sorogrupo A), S. flexneri (sorogrupo B), S. boydii (sorogrupo C) e S. sonnei (sorogrupo D) (FRANCO; LANDGRAF, 1996).

Shigellose é a doença infecciosa causada pelo grupo de bactérias do gênero Shigella; os sintomas são diarréia com sangue, febre, convulsões, cólicas abdominais, que aparecem num período de incubação de 1 a 2 dias após a contaminação, cuja duração é de 5 a 7 dias. Em crianças e idosos, a diarréia pode ser tão severa que os pacientes precisam ser hospitalizados. Algumas pessoas são infectadas, porém não apresentam sintomas, sendo importante na cadeia de transmissão (CDC, 2001).

É disseminada através da via fecal - oral, mas algumas vezes alimento e água participam como veículo. A Shigella apresenta resistência ao suco gástrico. Está sempre associada à higiene pessoal e condições sanitárias deficientes (VERONESI; FOCACCIA, 1999).

A toxina é responsável pela Síndrome Hemolítica Urêmica - HUS -, que se caracteriza por plaquetopenia e anemia microangiopática e falência renal, podendo ser fatal. Outra característica do bacilo Shiga, é sua capacidade de causar extensas epidemias. No Brasil, de acordo com Pereira e Leocádio Filho (1994), é alta a frequiência de isolamentos de Shigella em amostra fecal de pacientes diarréicos em hospitais. Entretanto, é praticamente nula a constatação do microrganismo na água e alimentos.

As complicações e letalidade da shigelose são baixas em países desenvolvidos, porém têm relevante importância em áreas endêmicas de comunidades em desenvolvimento, onde condições de saneamento básico e higiene pessoal são precárias, principalmente quando se trata de crianças desnutridas e idosos (VERONESI; FOCACCIA, 1999).

A shigelose pode causar as seguintes complicações: peritonite secundária à perfuração intestinal, insuficiência renal aguda, síndrome hemolítica urêmica e hemorragia digestiva; são menos usuais: pneumonia, conjuntivite, uveíte, úlcera de córnea, prolapso retal, osteomielite e artrite asséptica (VERONESI; FOCACCIA, 1999). 
As medidas de controle e prevenção das shigeloses de origem alimentar estão relacionadas com a boa higiene pessoal e educação dos manipuladores de alimento. A contaminação de alimentos ou água com Shigella sp indica contaminação recente com fezes humanas ( FRANCO; LANDGRAF ,1996 ).

\section{Escherichia coli Patogênica}

A Escherichia coli (E.coli) é espécie predominante da flora intestinal de animais de sangue quente. Pertence à família Enterobacteriacceae, são bacilos gram- negativos, não esporulados, apresentam diversas linhagens comprovadamente patogênicas para o homem e para animais (CAMARGO et al., 1998).

As linhagens de E.coli consideradas patogênicas são agrupadas em 5 classes (FRANCO; LANDGRAF, 1996) :

- EPEC (E. coli enteropatogênica clássica);

- EIEC (E. coli enteroinvasora);

- $\operatorname{ETEC~(E.~coli~enterotoxigênica);~}$

- EHEC (E. coli entero-hemorrágica);

- EaggEC (E. coli enteroagregativa).

EPEC está associada à diarréia infantil, sendo recém-nascidos e lactentes mais suscetíveis. A duração da doença varia entre 6 horas a 3 dias, com período de incubação variando de 17 a 72 horas (FRANCO; LANDGRAF ,1996) .

A doença causada pela $E$. coli enteropatogênica, é atribuída a uma toxina similar a da S. dysenteriae, também chamada verotoxina, ocasiona diarréia prolongada, levando à desidratação e morte, tem sido relatado $50 \%$ de mortalidade nos países de terceiro mundo (CÂMARA, 2002).

As cepas de EIEC são responsáveis pela disenteria bacilar, doença caracterizada por fezes muco sanguinolentas, capazes de penetrar em células epiteliais e causar manifestações clínicas semelhantes às infecções causadas por Shigella. O período de incubação varia entre 12 e 72 horas. O isolamento deste microrganismo em alimentos é extremamente difícil, porque mesmo níveis não detectáveis, causam a doença (CÂMARA, 2002).

E. coli enterotoxigênica causa gastroenterite; são cepas capazes de produzir enterotoxina, cujo efeito é uma diarréia aquosa, conhecida como diarréia dos viajantes (FDA, 2001). O período de incubação varia de 8 a 24 horas. Pode produzir uma enterotoxina termolábil, inativada a $60^{\circ} \mathrm{C}$ por trinta minutos e uma enterotoxina termoestável, que suporta $100^{\circ} \mathrm{C}$ por trinta minutos (FRANCO; LANDGRAF, 1996). 
EHEC produz uma colite hemorrágica que pode evoluir para HUS. O gado é reservatório natural da $E H E C$, razão pela qual os alimentos de origem animal, principalmente a carne bovina, parecem ser o principal veículo desse patógeno. (FRANCO; LANDGRAF, 1996).

A determinação da origem das doenças alimentares é complexa. Ela pode estar relacionada a diversos fatores ligados à cadeia epidemiológica de enfermidades transmissíveis, que envolvem a tríade agente-meio ambiente-hospedeiros suscetíveis. Atualmente, a transmissão de doenças infecciosas por alimentos constitui um evento freqüente, que, em algumas situações, pode apresentar elevada gravidade para um grande número de pessoas no Brasil e no mundo:

Os dados do Sistema de Informações Hospitalares (SIH) do Ministério da Saúde, de 1999 a 2004, mostram a ocorrência de 3.410.048 internações (CID 10 A00 a A09), com uma média de 568.341 casos por ano. (...) De acordo com o Sistema de Informação sobre Mortalidade (SIM), de 1999 a 2002, ocorreram 25.281 óbitos, com uma média de 6.320 óbitos/ano (SVS, 2005).

Apesar da comprovada relação de várias doenças com a ingestão de alimentos contaminados, do elevado número de internações hospitalares e da persistência de altos índices de mortalidade infantil por diarréia, em alguns estados do país, pouco se conhece da real magnitude do problema, pois os casos e surtos são dificilmente notificados.

\section{Sistema de vigilância epidemiológica das doenças transmitidas por alimentos}

Devido às conseqüências decorrentes das doenças transmitidas por alimentos, o Brasil ampliou as ações sobre a necessidade e a importância de um sistema de vigilância e da adoção de medidas para garantir a segurança alimentar. De acordo com a Secretaria de Vigilância em Saúde esses fatores, somados aos acordos internacionais, entre os quais se destacam os subscritos pelo Brasil na VII Reunião Interamericana de Saúde Ambiental de Nível Ministerial (RIMSA) e na XXXV Reunião do Conselho Diretor da OPAS, levaram a Secretaria de Vigilância em Saúde do Ministério da Saúde a desenvolver o Sistema Nacional de Vigilância Epidemiológica das Doenças Transmitidas por Alimentos (BRASIL, 2004). Esse sistema, implantado em 1999, em parceria com a Agência Nacional de Vigilância Sanitária, o Ministério da Agricultura Pecuária e Abastecimento e o Instituto Pan-Americano de Alimentos da OPAS, tem como objetivo geral reduzir a incidência dessas doenças no Brasil. 
Para os serviços de alimentação, que têm requisitos algumas vezes diferentes dos demandados pela indústria, pela diversidade de matéria-prima, linha de produção, equipamentos, utensílios, a Anvisa em 2004 regulamentou a produção dessas unidades por meio da RDC 216/04.

\section{A RDC como instrumento de controle da qualidade dos alimentos}

A oferta de alimentos isentos de agentes patogênicos que possam pôr em risco a saúde do consumidor assumiu mundialmente relevância em saúde pública. Nas últimas décadas, tem-se observado um aumento das doenças transmitidas por alimentos, relacionado a vários fatores como o desenvolvimento econômico, a globalização do comércio de alimentos, a intensificação da urbanização e a modificações dos hábitos alimentares dos consumidores, com aumento do consumo de alimentos frescos ou in natura, preferência por alimentos prontos ou semiprontos e o consumo de refeições fora do domicílio (CDC, 2004; ORLANDI; CHU D-MT; BIER; JACKSON, 2002).

Segurança alimentar, no seu aspecto qualitativo, significa a garantia do consumidor em adquirir um alimento com atributos de qualidade, livres de contaminantes de natureza química (pesticidas), biológica (organismos patogênicos), física (vidros e pedras), ou de qualquer outra substância que possa acarretar problemas à sua saúde (SPERS; KASSOUF, 1996).

Um ponto importante que deve ser levado em conta em serviços de alimentação é o cuidado com a qualidade dos alimentos e produtos em geral e seu correto recebimento, manuseio e armazenamento (TEICHMANN, 2000). Um único problema de contaminação nestas etapas pode acarretar conseqüências desastrosas para os clientes desse empreendimento. As empresas desse ramo devem buscar distribuição correta de acordo com os padrões mais eficazes de higiene em cada etapa do processo de fornecimento, para diminuir a face vulnerável do negócio. Dessa forma, os procedimentos de higiene devem ser objetivos importantes no processo de treinamento de pessoal. De acordo com Davies (1999) o principal alvo do programa de higienização é proteger a saúde do cliente; e, para alcançar tal condição, as empresas ainda têm muitos outros problemas internos, como, armazenamento dos insumos, controle dos estoques, programação da produção e treinamento de pessoal a considerar (AMFES, 1997).

Diante do cenário atual, globalizado e competitivo, explicam Zanella e Cândido (2002) que, para que os restaurantes garantam sua sobrevivência e manutenção no mercado, é necessária uma estratégia competitiva com o diferencial desejado pelos consumidores. É neste 
sentido que o presente ensaio apresenta a higiene como pré-requisito para a qualidade sanitária por ser esse um dos desafios constantes para as empresas de fornecimento de alimentos: a necessidade do aprimoramento e da melhoria contínua dos serviços prestados. Para isso, os gestores precisam de um planejamento que permita aos manipuladores adotarem procedimentos corretos contra a contaminação de alimentos (SANTOS; TONDO, 2000). Práticas adequadas de higiene dentro no ambiente de manipulação e o estabelecimento de normas de monitoramento do controle de qualidade viabilizam custos de produção e satisfazem os anseios dos consumidores (AMFES, 1997).

A Resolução de Diretoria Colegiada n. ${ }^{\circ}$ 216/04 é um instrumento legal elaborado com o intuito de estabelecer procedimentos de Boas Práticas (BP) para serviços de alimentação para garantir as condições higiênico-sanitárias dos alimentos preparados (BRASIL, 2004). O Manual de Boas Práticas para Serviços de Alimentação é um documento que deve descrever os requisitos fundamentais das práticas e técnicas higiênico-sanitárias, específico para cada estabelecimento, que subsidia as etapas operacionais e as ações da Vigilância Sanitária, estabelecendo os critérios de higiene e procedimentos operacionais padronizados (POP's) visando prevenir e proteger a saúde do consumidor, a saúde do trabalhador e, ainda preservar o meio ambiente (BRASIL, 1993; BRASIL, 1997; BRASIL, 2002; BRASIL, 2004).

De acordo com a RDC 216/04 os requisitos para uma unidade de serviço de alimentação compreende os seguintes aspectos: edificação, instalações, equipamentos, móveis e utensílios; higienização de instalações, equipamentos, móveis e utensílios; controle de vetores e pragas urbanas:abastecimento de água; manejo de resíduos; higiene e saúde dos manipuladores; matérias-primas, ingredientes e embalagens; preparação do alimento armazenamento e transporte do alimento preparado; exposição ao consumo do alimento preparado.

Para alguns desses itens as empresas devem ter também descritos os Procedimentos Operacionais Padronizados (POP's) e Instrução de Trabalho (IT): Higienização de instalações, equipamentos e móveis, Controle integrado de vetores e pragas urbanas, higienização do reservatório e higiene e saúde dos manipuladores. Os POP’s devem conter as instruções seqüenciais das operações e a freqüência de execução, especificando o nome, o cargo e ou a função dos responsáveis pelas atividades. Devem ser aprovados, datados e assinados pelo responsável do estabelecimento e mantidos por trinta dias a partir data de preparação dos alimentos (Anexo 2) (BRASIL, 2004).

A RDC privilegia os aspectos referentes à qualidade sanitária e o treinamento dos manipuladores. Dentre os itens referentes ao treinamento, a RDC sugere: 
a) Contaminantes alimentares;

b) Doenças transmitidas por alimentos;

c) Manipulação higiênica dos alimentos;

d) Boas Práticas.

O entendimento destes itens por parte dos manipuladores auxilia de forma construtiva e informativa, evitando assim problemas relacionados à contaminação dos alimentos.

\section{Manipuladores de Alimentos}

A maioria das doenças veiculadas por alimentos de origem microbiana deve-se à manipulação inadequada dos mesmos. A identificação de manipuladores de alimentos portadores de agentes patogênicos que podem ser propagados para os alimentos é uma ferramenta útil na prevenção da contaminação dos mesmos. Segundo a RDC 216/04 o termo "manipuladores de alimentos", num sentido amplo, corresponde a qualquer indivíduo que entre em contato com um produto alimentício, nas etapas de produção, processamento, embalagem, armazenamento, transporte, distribuição e venda de alimentos.

O Centers for Disease Control and Prevention (CDC, 2004) estima que, anualmente, nos Estados Unidos da América, as doenças transmitidas por alimentos acometem 76 milhões de pessoas, sendo que mais de 300 mil são hospitalizadas e 500 vão a óbito. Entre as principais causas de doenças de origem microbiana veiculadas por alimentos está a manipulação inadequada dos mesmos (ORLANDI; CHU D-MT; BIER; JACKSON, 2002). Portanto, os manipuladores desempenham função importante na preservação da higiene dos alimentos, pois podem representar uma importante fonte de transmissão de patógenos ou de deterioradores.

Entre os organismos patogênicos, os parasitas intestinais encontram-se distribuídos praticamente por todo o mundo, registrando elevados coeficientes de prevalência em populações com precárias condições higiênico-sanitárias. Estudos conduzidos em comunidades carentes da África, Turquia, Vietnã, México e Brasil, demonstraram taxas de infestação parasitária de 55,8\%,37,2\%, 88,0\%, 67,0\% e 79,0\%, respectivamente, com maiores freqüências de Ascaris lumbricoides, Ancilostomídeos, Trichuris trichiura e Giardia lamblia6-10 (SILVA et al., 2005).

Contudo, as infecções parasitárias intestinais são em sua maioria assintomáticas e, quando determinam alguma sintomatologia, esta é geralmente discreta e inespecífica, não sendo muitas vezes diagnosticada. Assim, o manipulador de alimentos parasitado e 
assintomático pode representar uma fonte de transmissão duradoura, podendo propagar os enteroparasitas para os alimentos através das mãos contaminadas. A identificação da ocorrência de enteroparasitoses em manipuladores pode contribuir na prevenção da contaminação de alimentos.

Araújo et al. (2003) explicam que as micoses em geral, apesar de não serem consideradas doenças de notificação obrigatória, são reconhecidas como problema de saúde pública em muitas partes do mundo. Sua prevalência está diretamente ligada às condições socioeconômicas, baixa higiene, condições sanitárias, idade, sexo, ocupação e profissão.

Paralelo a esse entendimento, acrescentam-se apontamentos acerca da onicomicose, que, embora não seja uma infecção relacionada com transmissão alimentar, o seu controle nos manipuladores de alimentos, torna-se importante para a manutenção de uma higiene adequada, pois a presença de micose ungueal pode também servir como porta de entrada para outros microrganismos, favorecendo a instalação de uma infecção secundária por bactérias, de onde podem ser propagadas para o alimento, contribuindo com a sua contaminação (SABIONI; HIROOKA; SOUZA, 1998).

Um dos fatores que influenciam na aderência e na multiplicação das bactérias na pele é a esfoliação da mesma. Portanto, a existência de onicomicoses pode favorecer o crescimento bacteriano no local das lesões, particularmente do Staphylococcus aureus, organismo originário essencialmente da pele do homem e dos animais. Nesse contexto, Silva et al, (2005) relatam que, entre as micoses cutâneas, a onicomicose é uma manifestação muito comum, sendo mais freqüente entre as mulheres, particularmente as que estão em maior contato com a água, como cozinheiras e lavadeiras, e, entre os homens, é mais comum nos lavadores de louças, manipuladores de hortaliças e frutas, jardineiros e outros.

Costa, Lima e Ribeiro (2002) explicam que a visão que associa a falta de higiene à pobreza e à ignorância tem impedido que profissionais de saúde e nutrição questionem pela raiz a estrutura social, cultural e econômica na qual atuam. Isto é, ao acusarem a falta de higiene do manipulador de alimentos no desempenho de sua função e ao valorizarem a freqüência das atividades educativas como solução para esse problema, eles evitam a discussão sobre os diversos níveis de determinação desse processo. Portanto, para que se obtenham boas práticas de higiene na manipulação de alimentos, é necessário investigar e atuar sobre todos os fatores, individuais e coletivos, comportamentais e ambientais, que condicionam essas práticas.

A escolha do consumidor está além da preferência pelo sabor e rapidez no atendimento. Hoje o consumidor sabe que a qualidade também está relacionada à segurança 
alimentar, à preservação dos princípios de higiene, à limpeza na preparação e manipulação dos alimentos, à qualidade dos insumos aplicados, aos equipamentos utilizados, ao ambiente de trabalho e especialmente aos cuidados imperceptíveis aos olhos.

Em alguns estabelecimentos a área de produção começa a ser "descortinada" para permitir ao cliente uma demonstração do que vem a ser qualidade em alimentação. Os serviços de limpeza de todos os ambientes, desinfecção da cozinha, locais de guarda de equipamentos e de estoque devem constituir preocupação permanente, não só para manter a qualidade do serviço, mas também para atender à exigência do serviço de fiscalização da saúde pública (SEBRAE, 2007).

O crescimento da atividade turística, a procura pelos serviços de alimentação, a abertura de hotéis com bandeiras internacionais e o intercâmbio de profissionais da área determinaram a busca desses conhecimentos e a prática diferenciada nos serviços. Nesse contexto, para garantir a inocuidade dos alimentos, é de suma importância identificar os potenciais perigos, especialmente originários do contato entre manipuladores e alimentos, que podem ser transmitidos para os alimentos, contribuindo para evitar a contaminação dos mesmos e para o comprometimento da saúde do consumidor.

\section{CONSIDERAÇÕES FINAIS}

A demanda por refeições fora de casa cresce espantosamente. Paralelo a isso, há igualmente um aumento nos danos à saúde pública no mundo por meio das DTA's. A conscientização dos manipuladores com os problemas existentes, seu devido treinamento, educação e principalmente a sua valorização, possibilitam diminuir o índice de doenças transmitidas por alimentos.

Apesar de obrigatória a adoção dos requisitos básicos das boas práticas, observa-se que a minoria dos serviços de alimentação ainda não segue os princípios estabelecidos na RDC 216/04. Parcerias com a vigilância sanitária e órgãos competentes, incentivos às empresas seguidoras do manual de boas práticas, a aproximação clientes e manipuladores de alimentos, são ações que possibilitam desenvolver estratégias para manter a inocuidade em todos os processos de produção de alimentos.

Para evitar as doenças transmitidas por alimentos é necessária à implementação conjunta de várias ações de fiscalização, e promoção de educação em higiene de alimentos para os manipuladores. Neste contexto, é de suma importância a identificação dos portadores de agentes patogênicos que possam ser propagados para os alimentos através da manipulação. 
Devido ao fato de a inocuidade dos alimentos serem relevante para a saúde pública, os pesquisadores corroboram para a importância da adequação dos serviços às normas legais, especialmente com relação à aplicação da RDC 216/04.

Os serviços de alimentação devem não apenas ter o Manual de Boas Práticas, de Procedimentos Operacionais Padronizados e as Instruções de Trabalho (IT), mas devem implementá-los e mantê-los sob controle diário. A conscientização dos riscos advindos de práticas inadequadas e da gravidade dos surtos que demandam o atendimento médico, hospitalizações, e algumas vezes levam a óbitos, podem ser minimizados por meio de procedimentos simples e seguros como o ato de lavar as mãos ao sair do banheiro. Treinar, educar ou reeducar os funcionários de estabelecimentos que trabalham com gêneros alimentícios é a base para a implantação de qualquer ferramenta de segurança alimentar.

Dessa perspectiva, o presente trabalho teve como proposta descrever de forma sucinta sobre a importância de medidas higiênico-sanitárias que assegurem o controle de perigos potencias na manipulação de alimentos. As orientações técnicas permitem aos gestores de serviços de alimentação o correto segmento da RDC 216/04, valorizando todas as ações, permitindo aos manipuladores e multiplicadores tornarem-se responsáveis e motivados a fornecer saúde em forma de alimentos seguros. 


\section{REFERÊNCIAS}

AKUTSU, R.C.; BOTELHO, R.A.; CAMARGO, E.B.; SÁVIO, K.E.O.; ARAÚJO, W.C. Adequação de boas práticas de fabricação em serviços de alimentação. Revista de Nutrição, Campinas, p. 419-427, maio/jun. 2005.

ALMEIDA, A. C. et al . Ocorrência de B. cereus em farinhas de mandioca comercializadas em Salvador-BA. In: XII Encontro Nacional de Analista de Alimentos. Maceió. Anais Maceió: ENAAL, 2001.

ALMEIDA, P.M.P.; FRANCO, R.M. Avaliação bacteriológica de queijo tipo minas frescal com pesquisa de patógenos importantes à saúde pública: Staphilococcus aureus, Salmonella sp e Coliformes fecais. Revista Higiene Alimentar, v. 17, nº 111, Ago, 2003.

AMFES, Iternational Association of Milk, Food and Environmental Sanitarians. Guia de Procedimentos para Implantação do Método de Análise de Perigos em Pontos Críticos de Controle (APPCC). São Paulo: Ponto Crítico Consultoria em Alimentação, 1997.

ANDRADE, N. J de; MACEDO, J. A. B. de. Higienização na indústria de alimentos. São Paulo: Livraria Varela, 1996.

ARAÚJO, A.J.G.; BASTOS, O.M.P.; SOUZA, M.A.J.; OLIVEIRA, J.C. Onicomicoses por fungos emergentes: análise clínica, diagnóstico laboratorial e revisão. no 78 . An Bras Dermatol, 2003.

CAMARGO, N. J.; SOUZA, I.L.; PUZYNA, I. P.; PESTANA, A; NERVINO, C.V.; HIROOKA, E.Y.; OLIVEIRA, T.C.R.M. Avaliação epidemiológica de surtos de doenças transmitidas por alimentos no Estado do Paraná entre 1978 e 1997 In: V Congresso LatinoAmericano de Microbiologia e Higiene de Alimentos, 11, 1998, Águas de Lindóia. Anais: Águas de Lindóia - SP, 1998.

CHAVES, Neuma. VEDTA - Vigilância Epidemiológica das Doenças Transmitidas por Alimentos. s/d. Disponível em: < iwWw.saude.mS.gov.br/externo/downloads/aulaVEDTA.pdf $>$ Acesso em: 20.5.2008.

CENTERS FOR DISEASE CONTROL AND PREVENTION - CDC. Diagnosis and management of foodborne illnesses: a primer for physicians. $\mathrm{n}^{\circ}$ 53. MMW Recomm Rep 2004.

CENTRO DE VIGILÂNCIA EPIDEMIOLÓGICA - CVE. Doenças Transmitidas por Água e Alimentos, em Dados Estatísticos (Tabelas de Surtos). InformeNet - Tabelas de Surtos 19992002. Disponível em: <'http://WWW.cve.saude.sp.gov.biti > Acesso em: 21.9.2008. 
COSTA, E. de Q.; LIMA, E. da S. e RIBEIRO, V. M. B. The training of public school cafeteria staff: an analysis of the instructional material developed by Instituto de Nutrição Annes Dias. Rio de Janeiro (1956-94). História, Ciências, Saúde. Manguinhos, vol. 9(3), Sept.-Dec. 2002.

DAVIES. Carlos Alberto. Alimentos \& Bebidas. Caxias do Sul: EDUCS, 1999.

FLANDRIN, Jean-Louis; MONTANARI, Massimo (orgs). A História da Alimentação. Disponível em: < http://WwW.cchla.ufpb.br/ppgh/PPGH_2006-1 TE_Cultura_Material.pdfi > Acesso em: 19.4.2008.

FRANCO, G. M. B.; LANDGRAF, M. Microbiologia dos Alimentos. São Paulo: Atheneu, 1996.

GREEN, Cynthia. Os Caminhos da Qualidade [trad. Sara S. Gedanke] São Paulo: Makron Books, 1995.

HOBBS, Betty C. Toxinfecções e Controle Higienico-Sanitário de Alimentos. São Paulo: Livraria Varela, 1998.

IBGE 2002-2003. Pesquisa de Orçamento Familiar - POF 2002-2003, Instituto Brasileiro de Geografia http://www.sidra.ibge.gov.br/bda/pesquisas/pof/default20022003.asp?z=p\&o=8-i> Acesso em 07.07 .2008 .

INSTITUTO ETHOS - Empresas e Responsabilidade Social. Publicações Ethos. Disponível em: $\langle$ http://Www.ethos.org.brri. Acesso em: 10.07.2008

MANUAL VEDTA - Manual Integrado de Prevenção e Controle de Doenças Transmitidas por Alimentos. Fundação Nacional de Saúde, Centro Nacional de Epidemiologia. Disponível em < bvsms.saude.gov.br/bvs/publicacoes/ManuaVEDTA.pdf > Acesso em 07.07.2008

MARQUES, J. Albano. Manual de Hotelaria: políticas e procedimentos. Rio de Janeiro: Thex, 2000.

OLIVEIRA, Luciel Henrique de; CAMPOS, Benedito Marques. Porter e a Competitividade dos Restaurantes Self-Services: um estudo exploratório. Seminários em Administração FEAUSP. SEMEAD. Anais... São Paulo: IX SEMEAD, Agosto/2006. Disponível em: < WWW.administradores.com.br/.../431/download/ > Acesso em: 20.05.2008. 
ORGANIZAÇÃO PANAMERICANA DA SAÚDE - OPAS. HACCP: Instrumento Essencial para a Inocuidade de Alimentos. Buenos Aires, Argentina: OPAS/INPPAZ, 2001.

ORLANDI, P.A.; CHU D-MT; BIER, J.W.; JACKSON, J.G. Parasites and the food supply. $\mathrm{n}^{\mathrm{o}}$ 56. Foodtechnology, 2002.

PARDI, Miguel Cione. Ciência e Higiene - tecnologia da carne. Goiânia. CEGRAF UFG/Niteroi: EDUFF. 1993.

PEREIRA, M.L \& LEOCÁDIO FILHO, G. Surto infeccioso por Shiguella flexneriem Belo Horizonte , MG - Brasil - estudo de um caso. Higiene Alimentar, v. 8, n. 32, 1994.

PORTARIA n ${ }^{\circ}$ 1.428/MS, de 26.11.1993. Diário Oficial [da] República Federativa do Brasil: Brasília, 2.12.1993. Disponível em:

< $\quad$ 'http://WWW.cefeteg.br/superior/pos_graduacao/arquivos/Portaria\% 201428 $93 \% 20 \mathrm{MS} \% 20 \mathrm{APPCC}$.pdf $>$ Acesso em: 20.05.2008.

PORTARIA SVS/MS no 326, de 30.7.1997. Regulamento Técnico sobre as Condições Higiênico-Sanitárias e de Boas Práticas de Fabricação para Estabelecimentos Produtores/Industrializadores de Alimentos. Diário Oficial [da] República Federativa do Brasil: _ _ _ _ Brasília, _ _ _ _ 1.8.1997. _ _ Disponível < http://www.abic.com.br/arquivos/leg portaria326 97 anvisa.pdfi $\quad>; \quad$ e, < http://www.anvisa.gov.br/legis/portarias/326 97.htm > Acesso em: 20.05.2008.

PREFEITURA SP, 2008. Caracterização das Principais Doenças Transmitidas por Alimentos. Sítio da Prefeitura da cidade de São Paulo _ SP. Disponível em: < http://ww2.prefeitura.sp.gov.br//arquivos/secretarias/saude/vigilancia_saude/alimentos/0008/ DTA.pdf > Acesso em 15.07.2008

REBELATO, Marcelo Giroto. Uma análise sobre a estratégia competitiva e operacional dos restaurantes self-service. Revista Gestão \& Produção. Volume 04, nº 03, dezembro/1997.

RESOLUÇÃO RDC No 216, de 15.9.2004. Dispõe sobre Regulamento Técnico de Boas Práticas para Serviços de Alimentação. Agência Nacional de Vigilância Sanitária - ANVISA. Disponivel em: <'http://Www.tresiambiental.com.br/article.php3 22.05.2008.

RESOLUÇÃO RDC No 275, de 21.10.2002. Dispõe sobre o Regulamento Técnico de Procedimentos Operacionais Padronizados aplicados aos Estabelecimentos Produtores/Industrializadores de Alimentos e a Lista de Verificação das Boas Práticas de Fabricação em Estabelecimentos Produtores/Industrializadores de Alimentos. Diário Oficial 
[da] República Federativa do Brasil: Brasília, 6.11.2002. Disponível em: < http://WWw.abic.com.br/arquivos/leg_resolucao275 02 anvisa.pdfi > Acesso em: 22.05.2008.

SABIONI, J.G.; HIROOKA, E.Y.; SOUZA, M.L.R. Intoxicação alimentar por queijo minas contaminado com Staphylococcus aureus. nº 22. Revista da Saúde Pública, 1998

SANTOS, Mirian Isabel Souza, TONDO, Eduardo César. Determinação de Perigos e Pontos Críticos de Controle para implantação de sistema de Análise de perigos e pontos críticos de controle em lactário. Revista da Nutrição. vol. 13, n³. São Paulo, 2000.

SEBRAE. Segurança e Qualidade de Alimentos. Uma Ferramenta para Competitividade no Setor Alimentício Brasileiro. Curso "Programa de Alimentos Seguros - PAS". São Paulo, 24.04.2007.

SECRETARIA DE VIGILÂNCIA EM SAÚDE - SVS. Doenças Transmitidas por Alimentos (DTA). Vigilância Epidemiológica das Doenças Transmitidas por Alimentos no Brasil, 1999 - 2004. Boletim Epidemiológico. Ano 5, $\mathrm{n}^{\mathrm{o}}$ 06. 28.12.2005.

SILVA, Carolina Costa et al. Toxinfecção Alimentar por Salmonella em Evento Científico, São Paulo-SP,setembro de 2004. Informe Mensal sobre Agravos à Saúde Pública. Boletim Epidemiológico Paulista - BEPA. Ano I, nº 11. Novembro, 2004.

SILVA, Jaqueline Otero; CAPUANO, Divani M.; TAKAYANAGUI, Osvaldo M.; GIACOMETTI JÚNIOR, Eugênio. Enteroparasitoses e Onicomicoses em Manipuladores de Alimentos do Município de Ribeirão Preto. $\mathrm{n}^{\circ}$ 8. Revista Brasileira de Epidemiologia, 2005. vol. 4.

SILVA, Adriane Ribeiro da. et al. Qualidade Ambulante: uma experiência de melhoria do trabalho pela higiene alimentar. IX Simpósio Internacional Processo Civilizador. Tecnologia e Civilização. Ponta Grossa, Paraná. s/d.

SILVA JÚNIOR, Enio Alves da. Manual de Controle higiênico - sanitário em alimentos. São Paulo: Livraria Varela. 2002.

SPANG, Rebecca L. A Invenção do Restaurante. Jornal Folha de São Paulo. 24.9.2002 (a). Disponível em: < http://Www1.folha.uol.com.br/folha/sinapse/ult1063u97.shtml $>$ Acesso em: 20.05.2008.

SPANG, Rebecca L. A Invenção do Restaurante. Rio de Janeiro: Record, 2002 (b).

SPERS, E. E. \& KASSOUF, A. L. A Segurança dos Alimentos: Uma Preocupação Crescente. Higiene Alimentar, v. 10, n. 44, p. 18-21, jul/ago 1996. UNILEVER. Informativo Encontro Unilever Brasil, Junho 2001. 
SVS - Secretaria de Vigilância em Saúde, 2005. BOLETIM eletrônico EPIDEMIOLÓGICO. Disponível em:

$<$ portal.saude.gov.br/portal/arquivos/pdf/bol_epi_6_2005_corrigido.pdf > Acesso em: 15.07.2008.

TEICHMANN, Ione. Tecnologia Culinária. Caxias do Sul: EDUCS, 2000.

TRABULSI, L.R.; CAMPOS, L.C.; LORENÇO, R. Salmoneloses. In: VERONEZI, R. \& FOCACCIA, R. Tratado de Infectologia. São Paulo: Atheneu, 1996, Vol. 1.

US FDA. FOOD SAFETY A TO Z REFERENCE GUIDE. U.S. Food and Drug Administration Center for Food Safety and Applied Nutrition National Science Teachers Association, 2001. Disponível em: < http://Vm.cfsan.fda.gov/ dms/a2z-s.htmil > Acesso em: 21.09.2008.

VENTURI, I.; SANT'ANNA, L.C.; CRISPIM, S.P.; BRAMORSKI, A.; MELLO, R.M.A.V de. Treinamento para conservação e higiene dos alimentos: uma proposta para a prática educativa. Revista Higiene Alimentar, São Paulo, v. 18, n. 125, p. 32-35, out. 2004.

VERONESI, R.; FOCACCIA, R. Shigeloses. Tratado de Infectologia. São Paulo: Atheneu, 1999.

VIGARELLO, Georges. O Limpo e o Sujo. Uma história da higiene corporal. São Paulo: Martins Fontes, 1996.

WIKIPEDIA: A Enciclopédia Livre. Ensaio. [S.1.]: [s.n.], 2008. Disponível em: hittp://pt.wikipedia.org/wiki/Ensaiò. Acesso em: 20.10.2008.

ZANARDI, A.M.P. Garantia da Qualidade Higiênico Sanitária. In: ABREU, E.S. de et al. Gestão de Unidades de Alimentação e Nutrição: um modo de fazer. São Paulo: Metha, 2003.

ZANELLA, Luiz Carlos; CÂNDIDO, Índio. Restaurante: técnica e processos de administração e operação. Caxias do Sul: EDUCS, 2002. 
ANEXO 1

Quadro 1: Tabela com resumo das principais doenças transmitidas por alimentos.

\begin{tabular}{|c|c|c|c|c|}
\hline Agente Etiológico & $\begin{array}{l}\text { Período de } \\
\text { Incubação }\end{array}$ & Sinais e Sintomas & $\begin{array}{l}\text { Principais } \\
\text { Alimentos } \\
\text { envolvidos }\end{array}$ & $\begin{array}{l}\text { Principais fatores que } \\
\text { contribuem para a } \\
\text { ocorrência de surtos }\end{array}$ \\
\hline Bacillus cereus & $30^{\prime}$ a $5 \mathrm{~h}$ & $\begin{array}{l}\text { Náuseas, vômitos, } \\
\text { ocasionalmente } \\
\text { diarréia, dores } \\
\text { abdominais. }\end{array}$ & $\begin{array}{l}\text { Arroz cozido ou } \\
\text { frito, produtos ricos } \\
\text { em amido, molhos, } \\
\text { pudins, sopas. }\end{array}$ & $\begin{array}{ll}\text { Manutenção } & \mathrm{de} \\
\text { alimentos prontos em } \\
\text { tempo/temperatura } \\
\text { inadequados. }\end{array}$ \\
\hline $\begin{array}{l}\text { Bacillus cereus (tipo } \\
\text { diarréico) }\end{array}$ & 8 a $16 \mathrm{~h}$ & $\begin{array}{l}\text { Diarréia aquosa, dores } \\
\text { abdominais, náuseas, } \\
\text { vômitos raramente. }\end{array}$ & $\begin{array}{l}\text { Carnes, } \quad \text { leite, } \\
\text { vegetais } \\
\text { produtos de cereais. }\end{array}$ & $\begin{array}{l}\text { Manutenção } \\
\text { alimentos prontos em } \\
\text { tempo/temperatura } \\
\text { inadequados, } \\
\text { reaquecimento } \\
\text { insuficiente. }\end{array}$ \\
\hline Staphylococcus aureus & $1 \mathrm{a} 8 \mathrm{~h}$ & $\begin{array}{l}\text { Náuseas, vômitos, } \\
\text { dores abdominais, } \\
\text { diarréia, prostração. }\end{array}$ & $\begin{array}{l}\text { Produtos da carne, } \\
\text { frango, produtos de } \\
\text { confeitaria, doces e } \\
\text { salgados; produtos } \\
\text { muito manipulados. }\end{array}$ & $\begin{array}{l}\text { Contaminação do } \\
\text { alimento por } \\
\text { manipuladores, } \\
\text { equipamentos, } \\
\text { utensílios; manutenção } \\
\text { de alimentos prontos } \\
\text { em tempo/temperatura } \\
\text { inadequados. }\end{array}$ \\
\hline $\begin{array}{l}\text { Clostridium } \\
\text { perfringens }\end{array}$ & 8 a $22 \mathrm{~h}$ & $\begin{array}{l}\text { Dores } \\
\text { intensas, } \\
\text { gases. }\end{array}$ & $\begin{array}{l}\text { Carnes cozidas ou } \\
\text { assadas, molhos, } \\
\text { sopas. }\end{array}$ & $\begin{array}{l}\text { Descongelamento em } \\
\text { temperatura } \\
\text { inadequada, } \\
\text { resfriamento lento, } \\
\text { reaquecimento } \\
\text { insuficiente. }\end{array}$ \\
\hline Salmonella spp & 6 a $72 \mathrm{~h}$ & $\begin{array}{lr}\begin{array}{l}\text { Dores } \\
\text { diarréia, }\end{array} & \text { abdominais, } \\
\text { febre, } & \text { náuseas, } \\
\text { vômitos, } & \text { mal-estar, } \\
\text { dores } & \text { musculares, } \\
\text { cefaléia. } & \end{array}$ & $\begin{array}{l}\text { Carne bovina e de } \\
\text { aves, produtos à } \\
\text { base de ovos crus } \\
\text { (sem cocção). }\end{array}$ & $\begin{array}{l}\text { Matéria-prima } \\
\text { contaminada na } \\
\text { origem, contaminação } \\
\text { cruzada de ingredientes } \\
\text { crus de origem animal, } \\
\text { manutenção de } \\
\text { alimentos prontos em } \\
\text { tempo/temperatura } \\
\text { inadequados. }\end{array}$ \\
\hline Clostridium botulinum & $2 \mathrm{~h}$ a 8 dias & $\begin{array}{l}\text { Vertigem, visão dupla } \\
\text { ou borrada, boca seca, } \\
\text { dificuldade para } \\
\text { deglutir, falar, respirar; } \\
\text { fraquezar muscular, } \\
\text { constipação, dilatação } \\
\text { das pupilas, paralisia } \\
\text { respiratória, sintomas } \\
\text { gastrintestinais podem } \\
\text { preceder } \\
\text { neurológicos. } \\
\text { Frequentemente evolui } \\
\text { para óbito. }\end{array}$ & $\begin{array}{l}\text { Conservas } \\
\text { (principalmente as } \\
\text { caseiras) de } \\
\text { vegetais, peixes, } \\
\text { carnes. }\end{array}$ & $\begin{array}{l}\text { Elaboração inadequada } \\
\text { de alimentos em } \\
\text { conservas. }\end{array}$ \\
\hline
\end{tabular}




\begin{tabular}{|c|c|c|c|c|}
\hline $\begin{array}{l}\text { Vibrio } \\
\text { parahaemolyticus }\end{array}$ & 2 a $48 \mathrm{~h}$ & $\begin{array}{l}\text { Dores abdominais, diarréia, } \\
\text { náuseas, vômitos, febre, } \\
\text { calafrio, cefaléia. }\end{array}$ & $\begin{array}{l}\text { Pescados de origem } \\
\text { marinha, } \\
\text { geralmente } \\
\text { ingeridos crus. }\end{array}$ & $\begin{array}{l}\text { Refrigeração inadequada, } \\
\text { cozimento insuficiente, } \\
\text { contaminação cruzada. }\end{array}$ \\
\hline $\begin{array}{l}\text { Listeria } \\
\text { monocytogenes }\end{array}$ & $\begin{array}{l}4 \text { a } 21 \\
\text { dias }\end{array}$ & $\begin{array}{l}\text { Febre, cefaléia, náuseas, } \\
\text { vômitos, aborto, meningite, } \\
\text { encefalite e sepsis. }\end{array}$ & $\begin{array}{l}\text { Leite, queijo fresco, } \\
\text { patê, } \quad \text { carnes } \\
\text { processadas. }\end{array}$ & $\begin{array}{l}\text { Cozimento inadequado; } \\
\text { falhas na pasteurização } \\
\text { do leite; refrigeração } \\
\text { prolongada. }\end{array}$ \\
\hline $\begin{array}{l}\text { Campylobacter } \\
\text { jejuni }\end{array}$ & 2 a 7 dias & $\begin{array}{l}\text { dores abdominais, diarréia } \\
\text { (frequentemente com muco } \\
\text { e sangue), cefaléia, mialgia, } \\
\text { febre, anorexia, náuseas, } \\
\text { vômitos, sequiela da } \\
\text { síndrome de Guillan-Barré. }\end{array}$ & $\begin{array}{l}\text { Leite cru, fígado de } \\
\text { boi, mariscos crus, } \\
\text { água. }\end{array}$ & $\begin{array}{l}\text { Ingestão de leite cru e } \\
\text { carnes de aves crua ou } \\
\text { semicrua; pasteurização } \\
\text { ou } \\
\text { inadequado; } \\
\text { contaminação cruzada; } \\
\text { manuseio de produtos } \\
\text { crus. }\end{array}$ \\
\hline $\begin{array}{l}\text { Escherichia coli } \\
\text { patogênica }\end{array}$ & 5 a $48 \mathrm{~h}$ & $\begin{array}{l}\text { Dores abdominais, diarréia, } \\
\text { vômitos, náuseas, cefaléia, } \\
\text { mialgia. }\end{array}$ & $\begin{array}{l}\text { Diversos alimentos, } \\
\text { água. }\end{array}$ & $\begin{array}{l}\text { Contaminação } \\
\text { manipuladores, } \\
\text { refrigeração insuficiente, } \\
\text { cocção } \text { inadequada, } \\
\text { limpeza e desinfecção } \\
\text { deficiente r de } \\
\text { equipamentos. }\end{array}$ \\
\hline $\begin{array}{l}\text { Escherichia coli } \\
\text { enterohemorragic } \\
\text { a ou } \\
\text { verotoxigenica }\end{array}$ & $\begin{array}{l}1 \text { a } 10 \\
\text { dias }\end{array}$ & $\begin{array}{l}\text { Diarréia aquosa, seguida de } \\
\text { diarréia sanguinolenta, dor } \\
\text { abdominal intensa, sangue } \\
\text { na urina, síndrome } \\
\text { hemolítico-urêmica. }\end{array}$ & $\begin{array}{l}\text { Hambúrguer, leite } \\
\text { cru, embutidos, } \\
\text { iogurte, } \quad \text { alface, } \\
\text { água. }\end{array}$ & $\begin{array}{l}\text { Hambúrguer feito de } \\
\text { carne de animais } \\
\text { infectados; consumo de } \\
\text { carne e leite crús; } \\
\text { cozimento inadequado; } \\
\text { contaminação cruzada; } \\
\text { contaminação } \\
\text { manipuladores. }\end{array}$ \\
\hline $\begin{array}{l}\text { Escherichia coli } \\
\text { enteroinvasiva }\end{array}$ & $\begin{array}{l}1 / 2 \text { a } 03 \\
\text { dias }\end{array}$ & 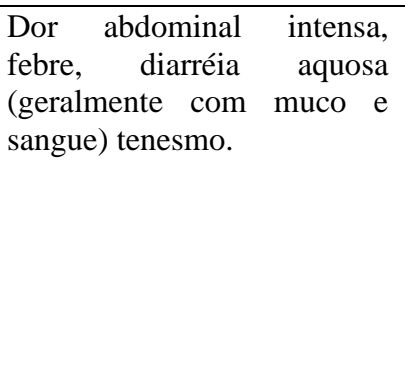 & $\begin{array}{lr}\text { Saladas e } & \text { outros } \\
\text { alimentos } & \text { não } \\
\text { higienizados, água. }\end{array}$ & $\begin{array}{lr}\text { Cozimento inadequado; } \\
\text { contaminação } & \text { por } \\
\text { manipuladores; } & \\
\text { armazenamento } & \text { de } \\
\text { alimento } & \text { em } \\
\text { temperaturas } & \\
\text { inadequadas; } & \\
\text { reaquecimento } \\
\text { insuficiente; resfriamento } \\
\text { lento. }\end{array}$ \\
\hline $\begin{array}{l}\text { Escherichia coli } \\
\text { enterotoxigênica }\end{array}$ & $\begin{array}{l}1 / 2 \text { a } 03 \\
\text { dias }\end{array}$ & $\begin{array}{l}\text { Diarréia aquosa profusa } \\
\text { (sem muco ou sangue); dor } \\
\text { abdominal intensa, vômitos, } \\
\text { prostração, desidratação, } \\
\text { febre leve. }\end{array}$ & $\begin{array}{lr}\text { Saladas e } & \text { outros } \\
\text { alimentos } & \text { sem } \\
\text { tratamento } & \\
\text { adequado, queijos } \\
\text { frescos, água. }\end{array}$ & $\begin{array}{lr}\text { Cozimento inadequado; } \\
\text { contaminação } & \text { por } \\
\text { manipuladores; } & \\
\text { armazenamento } & \text { de } \\
\text { alimentos } & \text { em } \\
\text { temperaturas } & \\
\text { inadequadas; } \\
\text { reaquecimento } \\
\text { insuficiente; resfriamento } \\
\text { lento; queijos fabricados } \\
\text { com leite cru. }\end{array}$ \\
\hline
\end{tabular}

Fonte: Prefeitura de São Paulo 
ANEXO 2

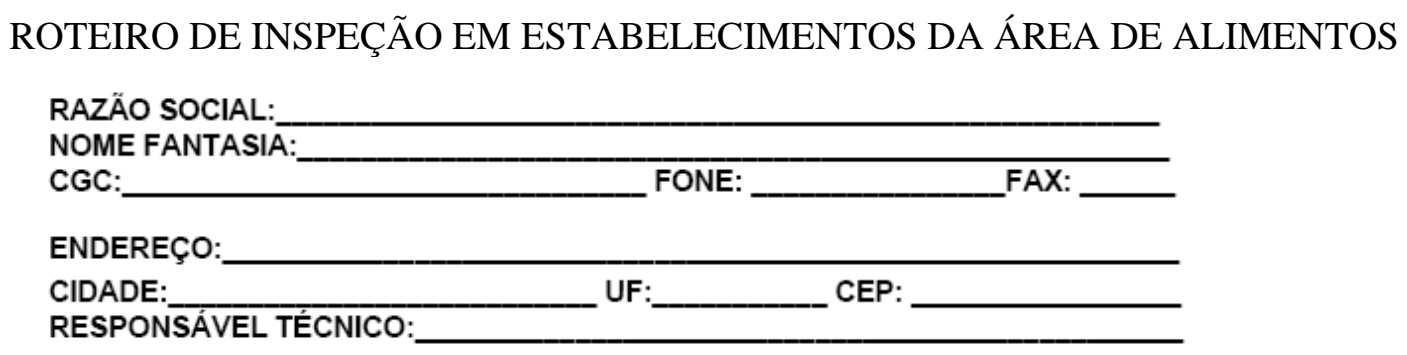

\begin{tabular}{|c|c|c|c|c|c|}
\hline \multirow[t]{2}{*}{ CLASS. } & \multicolumn{2}{|r|}{ ITENS AVALIADOS } & \multicolumn{3}{|c|}{ ATENDIMENTO } \\
\hline & & & SIM & NÅO & N. A. \\
\hline & 1 & Situação e condições da edificação & & & \\
\hline $\mathrm{R}$ & 1.1 & $\begin{array}{l}\text { Localização: Área livre de focos de insalubridade, ausência de } \\
\text { lixo, objetos em desuso, animais, insetos e roedores na área } \\
\text { externa e vizinhança. }\end{array}$ & & & \\
\hline $\mathrm{N}$ & 1.2 & $\begin{array}{l}\text { Acesso direto e independente, não comum a outros usos } \\
\text { (habitação). }\end{array}$ & & & \\
\hline & 1.3 & Pisos: & & & \\
\hline $\mathrm{N}$ & 1.3 .1 & $\begin{array}{l}\text { Material liso, resistente, impermeável, de fácil limpeza e em bom } \\
\text { estado de conservação (livre de defeitos, rachaduras, trincas e } \\
\text { buracos). }\end{array}$ & & & \\
\hline I & 1.3 .2 & Em perfeitas condições de limpeza & & & \\
\hline & 1.4. & Forros/tetos: & & & \\
\hline $\mathrm{N}$ & 1.4 .1 & $\begin{array}{l}\text { Acabamento liso, impermeável, lavável, em cor (ou tonalidade) } \\
\text { clara e em bom estado de conservação (livre de trincas, } \\
\text { rachaduras, umidade, bolor, descascamentos). }\end{array}$ & & & \\
\hline I & 1.4 .2 & Em perfeitas condições de limpeza. & & & \\
\hline & 1.5 & Paredes e divisórias: & & & \\
\hline $\mathrm{N}$ & 1.5 .1 & $\begin{array}{l}\text { Acabamento liso, impermeável, lavável, em cores (ou tonalidades) } \\
\text { claras e em bom estado de conservação (livre de falhas, } \\
\text { rachaduras, umidade, bolor, descascamentos). }\end{array}$ & & & \\
\hline I & 1.5 .2 & Em perfeitas condições de limpeza. & & & \\
\hline $\mathrm{N}$ & 1.6 & $\begin{array}{l}\text { Portas e janelas com superfície lisa, fácil limpeza, em bom } \\
\text { estado de conservação (ajustadas aos batentes, sem falhas de } \\
\text { revestimento e limpas). }\end{array}$ & & & \\
\hline $\mathrm{N}$ & 1.7 & $\begin{array}{l}\text { Existência de proteção contra insetos e roedores : Todas as } \\
\text { aberturas teladas (telas milimétricas), portas externas ou de } \\
\text { isolamento com fechamento automático e proteção inferior, bem } \\
\text { como sifão e proteção para os ralos. }\end{array}$ & & & \\
\hline $\mathrm{N}$ & 1.7 .1 & $\begin{array}{l}\text { Existência de desinsetização e desratização periódica por } \\
\text { empresa credenciada. Há comprovantes deste serviço. }\end{array}$ & & & \\
\hline
\end{tabular}

Observações: 


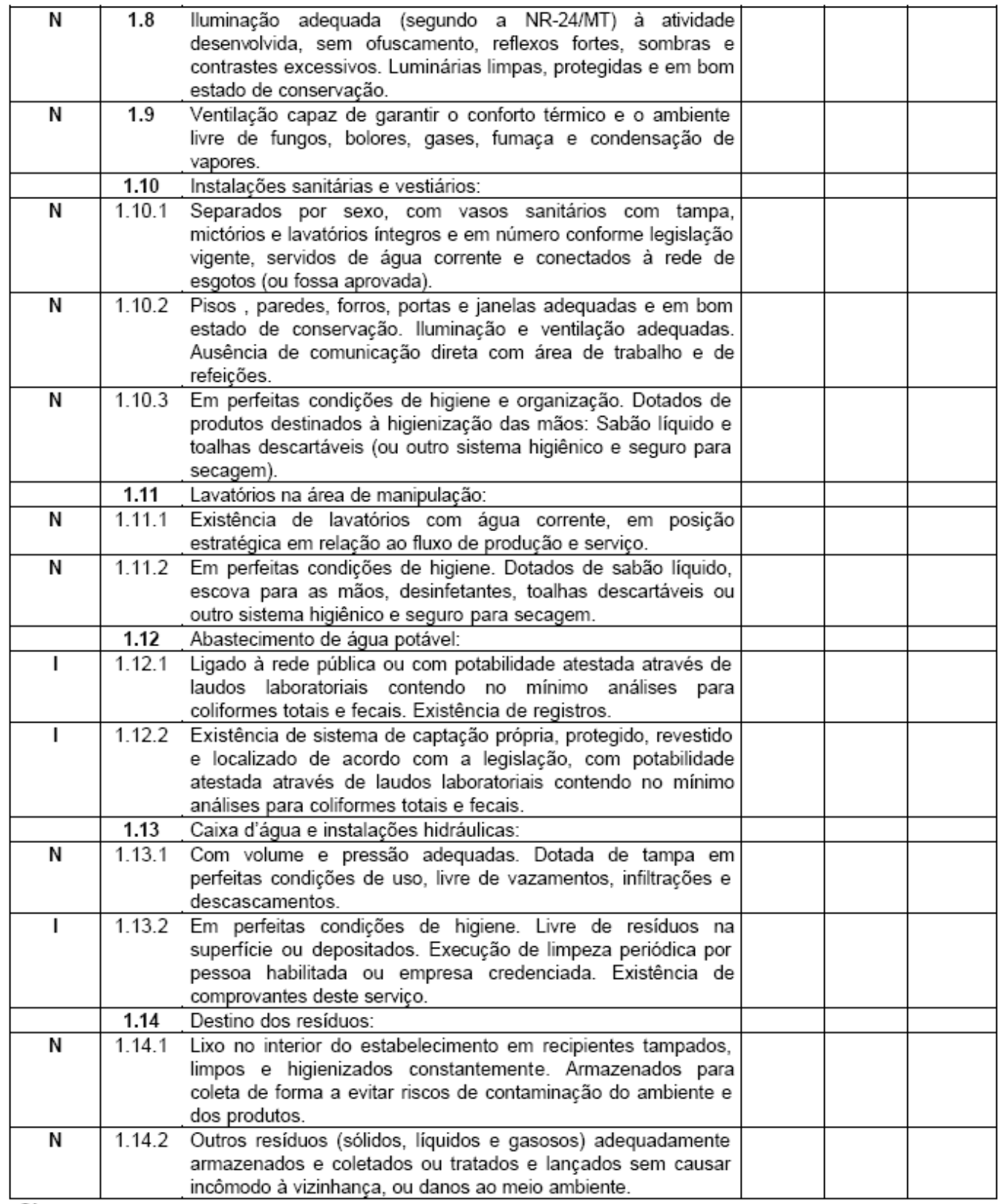

Obs: 


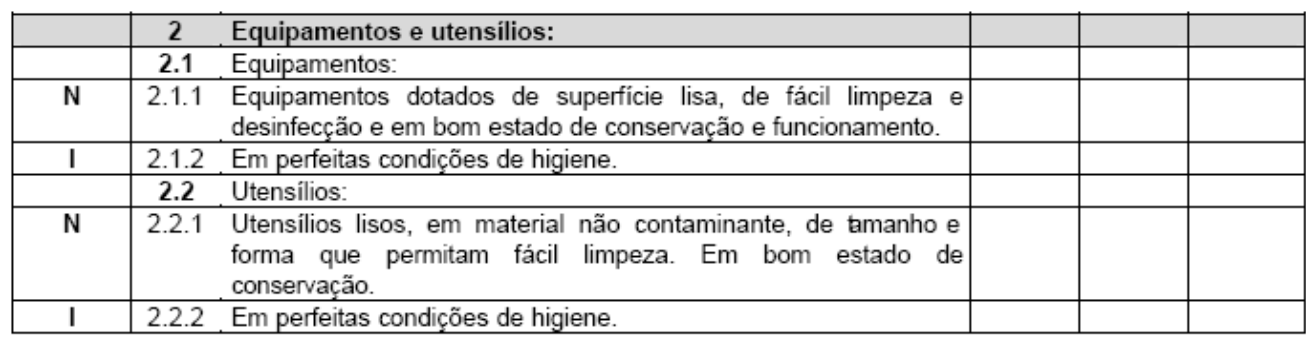

Observações

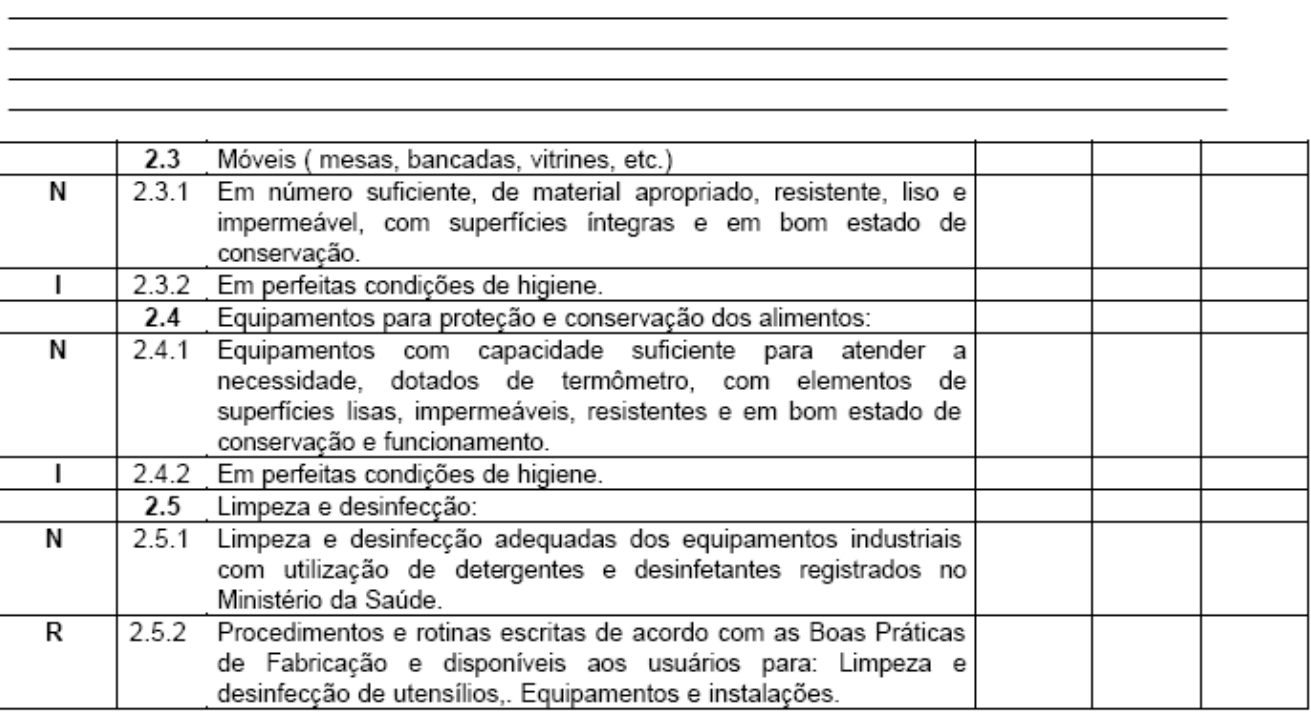

Observações: 


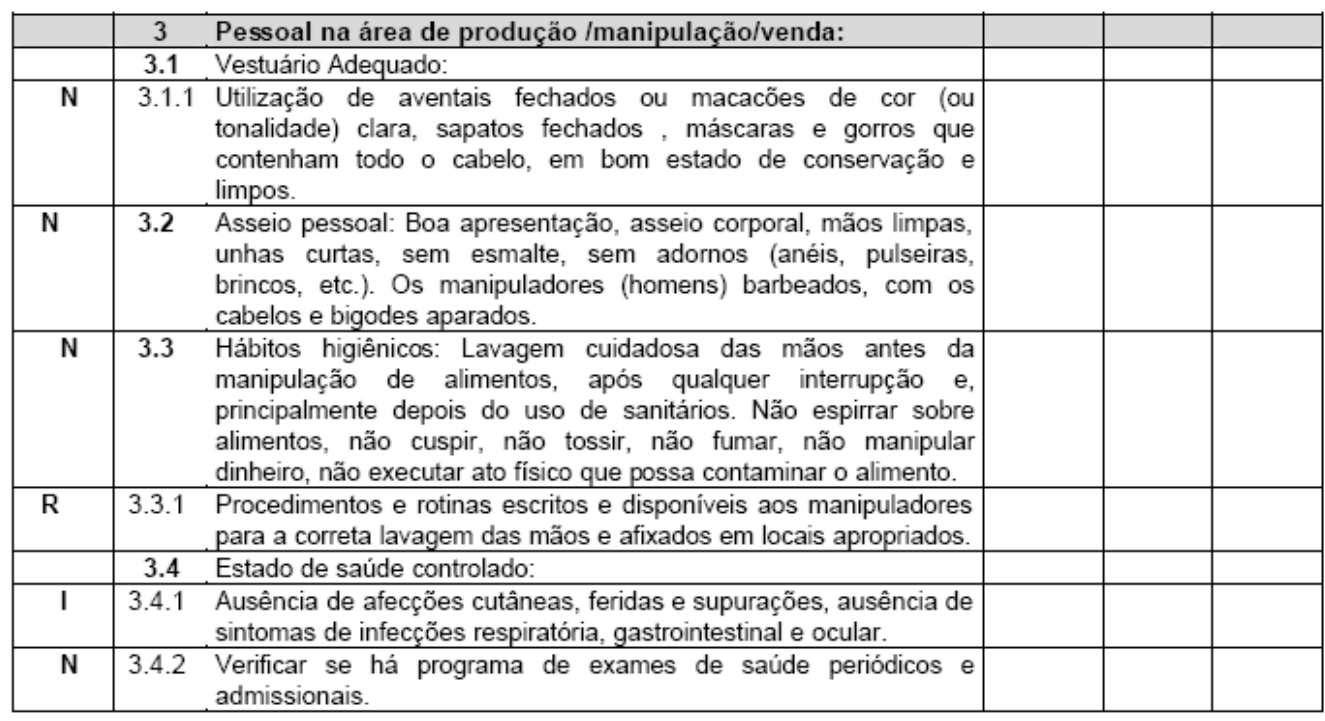

Observações

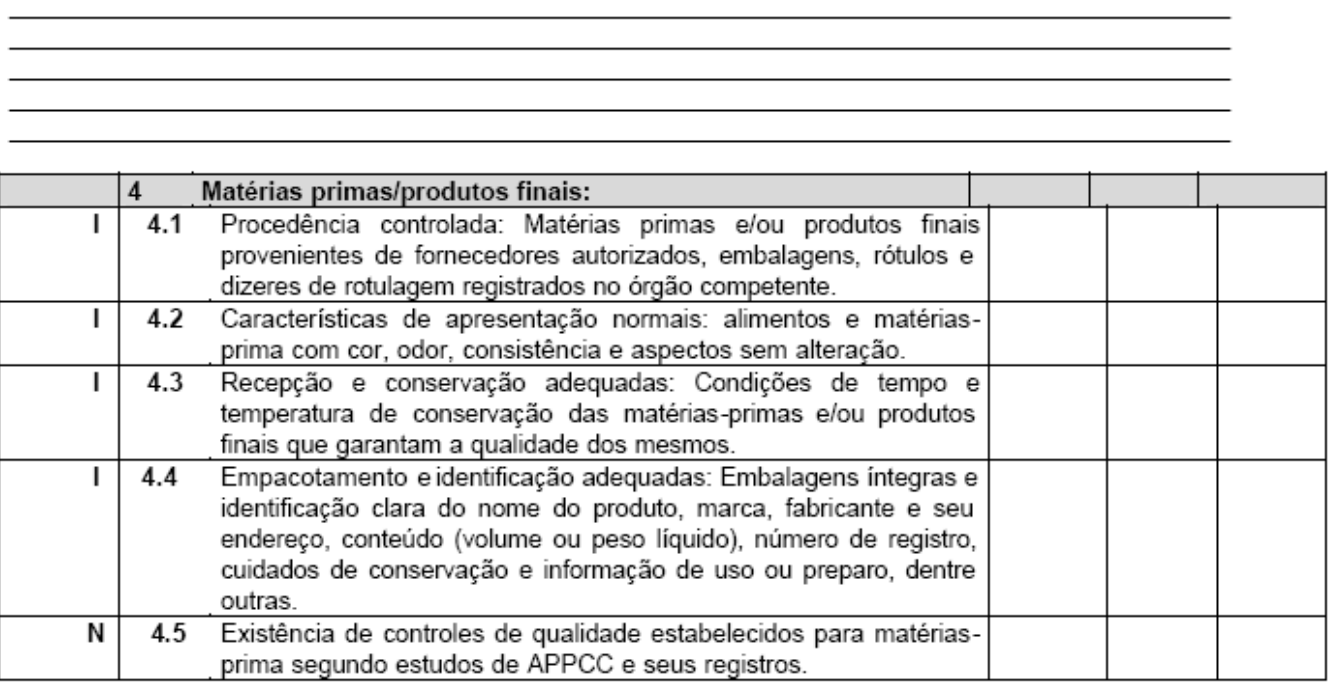

Observações: 


\begin{tabular}{|c|c|c|c|c|c|}
\hline & 5 & Fluxo de produção/manipulação e controle de qualidade: & & & \\
\hline & 5.1 & Fluxo: & & & \\
\hline $\mathrm{N}$ & 5.1 .1 & $\begin{array}{l}\text { Fluxo de sentido único, evitando a contaminação cruzada. Locais } \\
\text { para pré-preparo ("área suja") e preparo ("área limpa") isolados (a } \\
\text { separação física é necessária @m estabelecimentos com grande } \\
\text { produçấo). }\end{array}$ & & & \\
\hline $\mathrm{N}$ & 5.1 .2 & $\begin{array}{l}\text { Retirada freqüente dos resíduos e rejeitos das salas de produção, } \\
\text { evitando acúmulos. }\end{array}$ & & & \\
\hline & 5.2 & Proteção contra contaminação: & & & \\
\hline $\mathrm{N}$ & 5.2 .1 & Alimentos protegidos contra pó, saliva, insetos e roedores. & & & \\
\hline $\mathrm{N}$ & 5.2 .2 & $\begin{array}{l}\text { Substâncias perigosas como saneantes e domissanitários } \\
\text { (inseticidas, detergentes e desinfetantes), identificadas, } \\
\text { armazenadas e utilizadas de forma a evitar a contaminação. }\end{array}$ & & & \\
\hline & 5.3 & Armazenamento: & & & \\
\hline $\mathrm{I}$ & 5.3 .1 & $\begin{array}{l}\text { Alimentos pereciveis mantidos na temperatura de congelamento - } \\
18^{\circ} \mathrm{C} \text { (com tolerância até }-15^{\circ} \mathrm{C} \text { ), refrigeração (entre } 2 \text { e } 10^{\circ} \mathrm{C} \text { ), ou } \\
\text { aquecimento acima de } 65^{\circ} \mathrm{C} \text {, de acordo com o produto. }\end{array}$ & & & \\
\hline $\mathrm{R}$ & 5.3 .2 & $\begin{array}{l}\text { Alimentos armazenados separados por tipo ou grupo; sobre } \\
\text { estrados ou prateleiras de material de fácil limpeza, liso e integro, } \\
\text { com altura regulamentar, em local limpo e conservado. }\end{array}$ & & & \\
\hline $\mathrm{N}$ & 5.3 .3 & $\begin{array}{l}\text { Embalagens armazenadas em local exclusivo, seco, sobre } \\
\text { estrados de altura regulamentar ou prateleiras, dispostos de forma } \\
\text { que permitam a limpeza e impeçam a contaminação. }\end{array}$ & & & \\
\hline $\mathrm{N}$ & 5.3 .4 & $\begin{array}{l}\text { Armazenamento de utensilios e equipamentos em local apropriado, } \\
\text { de forma ordenada e protegidos de contaminação. }\end{array}$ & & & \\
\hline & 5.4 & Boas práticas de fabricação: & & & \\
\hline$R$ & 5.4 .1 & $\begin{array}{l}\text { O estabelecimento dispõe de manual de Boas Práticas de } \\
\text { Fabricação. }\end{array}$ & & & \\
\hline$R$ & 5.4 .2 & $\begin{array}{l}\text { Os manipuladores têm disponíveis as Boas Práticas de Fabricação } \\
\text { do seu setor e as colocam em prática. }\end{array}$ & & & \\
\hline & 5.5 & "APPCC": & & & \\
\hline$R$ & 5.5 .1 & $\begin{array}{l}\text { O estudo de APPCC é aplicado a cada linha de produtos. As } \\
\text { diferentes variações do mesmo (ex. sabor, formato) são incluidos } \\
\text { no mesmo estudo. }\end{array}$ & & & \\
\hline $\mathrm{R}$ & 5.5 .2 & $\begin{array}{l}\text { O estabelecimento dispõe de estudos de APPCC para todo o } \\
\text { processo. }\end{array}$ & & & \\
\hline $\mathrm{N}$ & 5.5 .3 & $\begin{array}{l}\text { Há responsável técnico habilitado para aplicar Boas Práticas de } \\
\text { Fabricação e controle dos Pontos Críticos }\end{array}$ & & & \\
\hline $\mathrm{R}$ & 5.5 .4 & $\begin{array}{l}\text { Os Pontos Críticos de Controle identificados são devidamente } \\
\text { controlados e há registros disponíveis. }\end{array}$ & & & \\
\hline$R$ & 5.5 .5 & $\begin{array}{lccccc}\text { Há rotinas escritas para as operações } & \text { principais da } \\
\text { produção/manipulação. }\end{array}$ & & & \\
\hline $\mathrm{N}$ & 5.5 .6 & $\begin{array}{l}\text { Há procedimentos para aferições e calibrações dos equipamentos } \\
\text { de mensuração dos Pontos Críticos de Controle (Termômetros, } \\
\text { manômetros, medidores de quantidades, etc.). Há registros destes } \\
\text { procedimentos. }\end{array}$ & & & \\
\hline $\mathrm{N}$ & 5.5 .7 & $\begin{array}{l}\text { Existência de supervisão periódica do estado de saúde e atuação } \\
\text { dos manipuladores (rotina de trabalho, etc) pela responsável da } \\
\text { empresa. }\end{array}$ & & & \\
\hline & 5.6 & Treinamento: & & & \\
\hline $\mathrm{N}$ & 5.6 .1 & $\begin{array}{l}\text { O pessoal envolvido nas operações do estabelecimento recebe } \\
\text { treinamento para exercício das atividades. Há registro destes } \\
\text { treinamentos }\end{array}$ & & & \\
\hline
\end{tabular}

Observações: 


\begin{tabular}{|l|ll|l|l|l|}
\hline & 6 & Transporte: & & & \\
\hline $\mathrm{N}$ & 6.1 & $\begin{array}{l}\text { Existência de procedimento de boas práticas para transporte de } \\
\text { matérias-primas e produtos de forma a impedir contaminação ou a } \\
\text { proliferação microorganismos e que protejam contra a alteração ou } \\
\text { danos às embalagens. Existência de registros. }\end{array}$ & & \\
\hline
\end{tabular}

Observações:

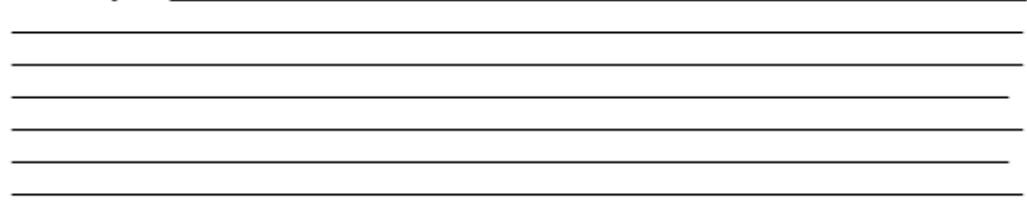

de de

Assinatura do Responsável Técnico 


\section{ANEXO 3}

\section{CLASSIFICAÇÃO DE CRITÉRIOS DE AVALIAÇÃO PARA OS ÍTENS DO ROTEIRO DE INSPEÇÕES}

\section{Classificação e critérios de avaliação:}

O critério estabelecido para a classificação está baseado no risco potencial inerente a cada item em relação à qualidade e segurança do produto e à segurança do trabalhador em sua interação com os produtos e processos.

\section{IMPRESCINDÍVEL - I}

Considera-se item IMPRESCINDÍVEL àquele que atende às Boas Práticas de Fabricação e Controle, que pode influir em grau crítico na qualidade ou segurança dos produtos e na segurança dos trabalhadores em sua interação com os produtos e processos.

\section{NECESSÁRIO - N}

Considera-se item NECESSÁRIO àquele que atende às recomendações das Boas Práticas de Fabricação e Controle, que pode influir em grau menos crítico na qualidade ou segurança dos produtos e na segurança dos trabalhadores em sua interação com os produtos e processos.

O item NECESSÁRIO, não cumprido na primeira inspeção, será automaticamente tratado como IMPRESCINDÍVEL nas inspeções seguintes.

\section{RECOMENDÁVEL - R}

Considera-se RECOMENDÁVEL àquele que atende às recomendações de Boas Práticas de Fabricação e Controle que pode influir em grau não crítico na qualidade ou segurança dos produtos e na segurança dos trabalhadores em sua interação com os produtos e processos.

O item RECOMENDÁVEL, não cumprido na primeira inspeção, será automaticamente tratado como NECESSÁRIO nas inspeções seguintes. Não obstante, nunca será tratado como IMPRESCINDÍVEL.

\section{INFORMATIVO - INF}

Considera-se como item INFORMATIVO àquele que apresenta uma informação descritiva, que não afeta a qualidade e a segurança dos produtos e a segurança dos trabalhadores em sua interação com os produtos e processos.

OBS.: Os itens avaliados devem ser definidos por SIM, NÃO e NÃO APLICÁVEL (N. A.), quando for o caso. 
This document was created with Win2PDF available at http://www.win2pdf.com.

The unregistered version of Win2PDF is for evaluation or non-commercial use only.

This page will not be added after purchasing Win2PDF. 